\title{
Sensitivity of Climate Simulations to Land-Surface and Atmospheric Boundary-Layer Treatments-A Review
}

\author{
J. R. GARRATT \\ CSIRO Division of Atmospheric Research, Aspendale, Victoria, Australia
}

(Manuscript received 6 June 1991, in final form 17 April 1992)

\begin{abstract}
Aspects of the land-surface and boundary-layer treatments in some 20 or so atmospheric general circulation models (GCMs) are summarized. In only a small fraction of these have significant sensitivity studies been carried out and published. Predominantly, the sensitivity studies focus upon the parameterization of landsurface processes and specification of land-surface properties-the most important of these include albedo, roughness length, soil moisture status, and vegetation density. The impacts of surface albedo and soil moisture upon the climate simulated in GCMs with bare-soil land surfaces are well known. Continental evaporation and precipitation tend to decrease with increased albedo and decreased soil moisture availability. For example, results from numerous studies give an average decrease in continental precipitation of $1 \mathrm{~mm} \mathrm{day}^{-1}$ in response to an average albedo increase of 0.13 . Few conclusive studies have been carried out on the impact of a gross roughness-length change-the primary study included an important statistical assessment of the impact upon the mean July climate around the globe of a decreased continental roughness (by three orders of magnitude). For example, such a decrease reduced the precipitation over Amazonia by 1 to $2 \mathrm{~mm}^{-1 a y^{-1}}$.

The inclusion of a canopy scheme in a GCM ensures the combined impacts of roughness (canopies tend to be rougher than bare soil), albedo (canopies tend to be less reflective than bare soil), and soil-moisture availability (canopies prevent the near-surface soil region from drying out and can access the deep soil moisture) upon the simulated climate. The most revealing studies to date involve the regional impact of Amazonian deforestation. The results of four such studies show that replacing tropical forest with a degraded pasture results in decreased evaporation $\left(\approx 1 \mathrm{~mm} \mathrm{day}^{-1}\right)$ and precipitation $\left(1-2 \mathrm{~mm} \mathrm{day}^{-1}\right)$, and increased near-surface air temperatures $(\approx 2 \mathrm{~K})$.

Sensitivity studies as a whole suggest the need for a realistic surface representation in general circulation models of the atmosphere. It is not yet clear how detailed this representation needs to be, but even allowing for the importance of surface processes, the parameterization of boundary-layer and convective clouds probably represents a greater challenge to improved climate simulations. This is illustrated in the case of surface net radiation for Amazonia, which is not well simulated and tends to be overestimated, leading to evaporation rates that are too large. Underestimates in cloudiness, cloud albedo, and clear-sky shortwave absorption, rather than in surface albedo, appear to be the main culprits.

There are three major tasks that confront the researcher so far as the development and validation of atmospheric boundary-layer ( $\mathrm{ABL}$ ) and surface schemes in GCMs are concerned:
\end{abstract}

(i) There is a need to assess critically the impact of "improved" parameterization schemes on GCM simulations, taking into account the problem of natural variability and hence the statistical significance of the induced changes.

(ii) There is a need to compare GCM simulations of surface and ABL behavior (particularly regarding the diurnal cycle of surface fluxes, air temperature, and ABL depth) with observations over a range of surface types (vegetation, desert, ocean). In this context, area-average values of surface fluxes will be required to calibrate directly the ABL/land-surface scheme in the GCM.

(iii) There is a need for intercomparisons of ABL and land-surface schemes used in GCMs, both for onedimensional stand-alone models and for GCMs that incorporate the respective schemes.

\section{Introduction}

The physical parameterization of land-surface and atmospheric boundary-layer ( $\mathrm{ABL})$ processes is required in numerical models of the atmosphere. The main objectives for developing realistic parameteriza-

Corresponding author address: Dr. J. R. Garratt, CSIRO Division of Atmospheric Research, Private Bag No. 1, Victoria 3195, Australia. tion schemes for use in general circulation models (GCMs) are as follows:

(i) To provide an efficient means of calculating the fluxes of momentum, heat, and water vapor, both at the surface and at several levels within the ABL. Knowledge of these fluxes in the lower atmosphere allows the vertical flux divergence to be calculated, and consequently the contribution of small-scale turbulence to the time rates of change of the mean wind, temperature, and humidity fields. 
(ii) To predict the ABL depth, and consequently the vertical redistribution of heat and mass.

(iii) To predict the depth and amount of ABL cloud, which subsequently interacts with the surface fluxes and evolving $\mathrm{ABL}$ depth.

The surface parameterization should include the effects of surface albedo (radiative transfer), surface roughness (momentum transfer), and surface hydrology (sensible and latent heat transfer; runoff). All of these properties are influenced by the presence of vegetation, by the presence of orographic features, and by the presence of surface heterogeneity, and all should be suitably represented in GCMs.

The inclusion of realistic soil and vegetation schemes in numerical dynamical models has taken on added importance in recent times because of the increased interest in land-use activities, and their impact on climate. The rapidly growing interest in climate and climate change problems, and the need to simulate regional climate more precisely on time scales of several decades, is leading to a greater appreciation of the role of the ABL and of the land surface in the climate system. It is generally accepted that in short-range numerical weather prediction models, the initialization problem and initial data deficiencies are more crucial than details of the model boundary-layer physics. In contrast, there is a recognition that climate is critically sensitive to the characteristics of the underlying surface (in particular, the albedo and moisture availability), and that the accuracy of the surface-flux formulation becomes more important for longer-range forecasts and for climate simulations.

In recent years, quite sophisticated turbulence, soil, and canopy schemes have been formulated for use in GCMs, and at the same time very detailed datasets have become available (e.g., Pitman et al. 1989) for specifying the geographical distribution of a range of surface parameters. These have not been universally adopted, and there exists some doubt as to the level of detail required in the typical GCM. Several major questions are raised when consideration is given to the role of the ABL and land-surface processes in the numerical simulation of climate-see, for example, Carson (1982a) and editorial comments on the paper of Henderson-Sellers and Gornitz (1984). These include the following:

(i) What are the important features of the ABL and surface that need to be included in numerical models of the atmosphere?

(ii) For a given model version, how well do model climatology and short-period model events compare with observations?

(iii) How are the results dependent on the model's time and space resolution?

(iv) Does an improvement in one parameterization scheme (e.g., soil hydrology, ABL mixing, clouds, radiation, and convection ) lead to a significant improve- ment in some aspects of the model fields? If not, what are the reasons?

(v) How good do other parameterizations need to be for the right model response to be achieved when a specific scheme is improved?

(vi) How should we assess and evaluate the impact of and the sensitivity of model simulations to a specific parameterization scheme?

(vii) Is a specific GCM appropriate for a given or desired sensitivity experiment?

(viii) How should statistical significance be evaluated?

(ix) What model fields or climatological parameters are best suited to assessing answers to the above?

Carson (1982b) has given a comprehensive review of land-surface and ABL schemes used in many GCMs up to circa 1980 , with an emphasis on surface processes. Other papers that complement this earlier review and tend to discuss specific topics in more detail, include Clarke (1970), Deardorff (1972), Smith and Carson (1977), Andre (1983), Laval (1988), Sommeria (1988), Rowntree (1988), and Avissar and Verstraete (1990).

The three land-surface properties-albedo, roughness, and hydrology (degree of wetness) - have all been the subject of individual sensitivity studies. In the real world, each of these properties varies significantly in space and time though it is not yet clear to what extent GCMs need to incorporate these natural variations. As an example, the albedo over snow-free land is known to vary between about $10 \%$ for tropical forest and $35 \%$ for desert. Figure 1 summarizes a range of values based on direct observations, model-derived values, and model-specified values that illustrates this. Likewise, the surface roughness over flat terrain can vary between $1 \mathrm{~mm}$ or less over sand and snow to $1-2 \mathrm{~m}$ over tall forests (Fig. 2). The roughness values are likely to be higher in the presence of small-scale orographic features.

Both Mintz (1984) and Rowntree (1983, 1988) have reviewed the climate sensitivity problem, confining their studies to the impact of land-surface boundary conditions on simulated climates. In addition, Laval (1986) summarized earlier work on the use of GCMs to study the impact of surface albedo on climate. In the Mintz (1984) review, later summarized and extended by Rowntree (1988), 11 studies were discussed with emphasis on surface albedo and soil moisture. To quote from Mintz's conclusions, "all of the experiments show that the atmosphere is sensitive to the land-surface evapotranspiration: so that changes in the available soil moisture or changes in the albedo produce large changes in the numerically simulated climates." Mintz's review in particular has stimulated a number of groups to improve land-surface schemes in GCMs, particularly regarding soil and canopy formulations.

This paper mainly focuses on the problem of land- 


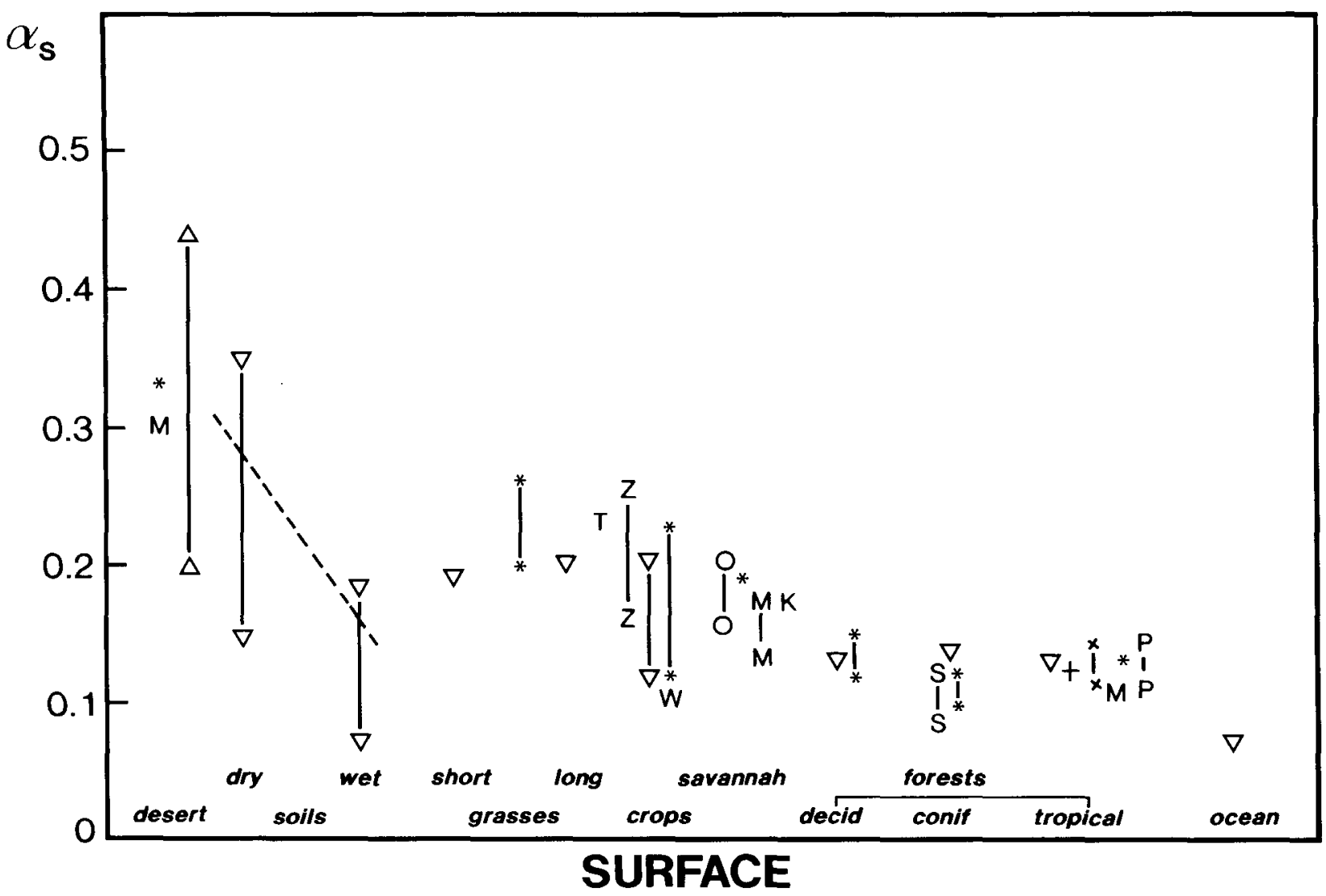

FIG. 1. Variation of albedo with surface type based on observations, literature values, and model-specified values. Data for both wet and dry soils, short and long grasses, and deciduous, coniferous, and tropical forests are shown. Vertical bars represent the range of albedo values for the specific surface type, while the dashed line represents the dependence of albedo upon surface moisture content given by Idso et al. (1975), namely,

$$
\alpha_{s}=0.31-0.34 \eta / \eta_{s} \text { for } \eta / \eta_{s} \leqslant 0.5
$$

and $\alpha_{s}=0.14$ for $\eta / \eta_{s}>0.5$. Data represent both direct observations and model-assumed values (themselves based on observations), with symbols as follows: $(*)$ from Dorman and Sellers $(1989)$, including a range of values for wheat $(W) ;(\nabla)$ from Wilson and HendersonSellers (1985), their Tables 8 and 9 -the ocean value is for a high zenith angle; $(\triangle)$ from Henderson-Sellers and Wilson (1983), their Table 4; (Z) from Sellers et al. (1986) for a wheat crop, giving the variation in albedo with zenith angle; (M) from Matthews (1985); (O) from Oguntoyinbo (1970); (T) from Tapper (1988); (K) from Kriebel (1979); (S) from Stewart (1971); (P) from Pinker et al. (1980); (X) from Dorman and Sellers (1989) (due to Monteny), see also Oguntoyinbo (1970); $(+)$ from Shuttleworth et al. (1984a).

surface representation and the sensitivity of GCM climate simulations to changes in land-surface properties. The emphasis throughout is on the land surface, so that problems associated with turbulence closure and ABL clouds are not treated extensively, mainly because sensitivity studies related to these are relatively few. It is assumed that the reader is familiar with basic definitions and concepts associated with the ABL and atmosphere-surface interaction (e.g., Brutsaert 1982; Stull 1988; Garratt 1992). The purpose of the paper is twofold: (i) to review the main ABL and land-surface parameterization schemes used in many contemporary GCMs, and (ii) to review the main sensitivity studies related to the impact of these schemes on climate simulations. The paper is an extension of the earlier reviews by Mintz and Rowntree and places greater emphasis upon the impact of canopy schemes and provides comprehensive information on GCM schemes and datasets. In section 2, the physical basis of flux formulations is described, with emphasis on surface processes. Section 3 deals with the boundary-layer schemes used in contemporary GCMs and is followed (section 4) by a description of the many datasets available for (i) specifying lower-boundary conditions and (ii) providing climatological data for comparison with model simulations. In section 5 the main sensitivity studies involving roughness and vegetation are summarized, while the results of studies involving the $\mathrm{ABL}$ in general are discussed in section 6 . The paper concludes with some comments on the outcomes of model deforestation experiments ( section 7) followed by an overall summary of those areas where increased knowledge is 


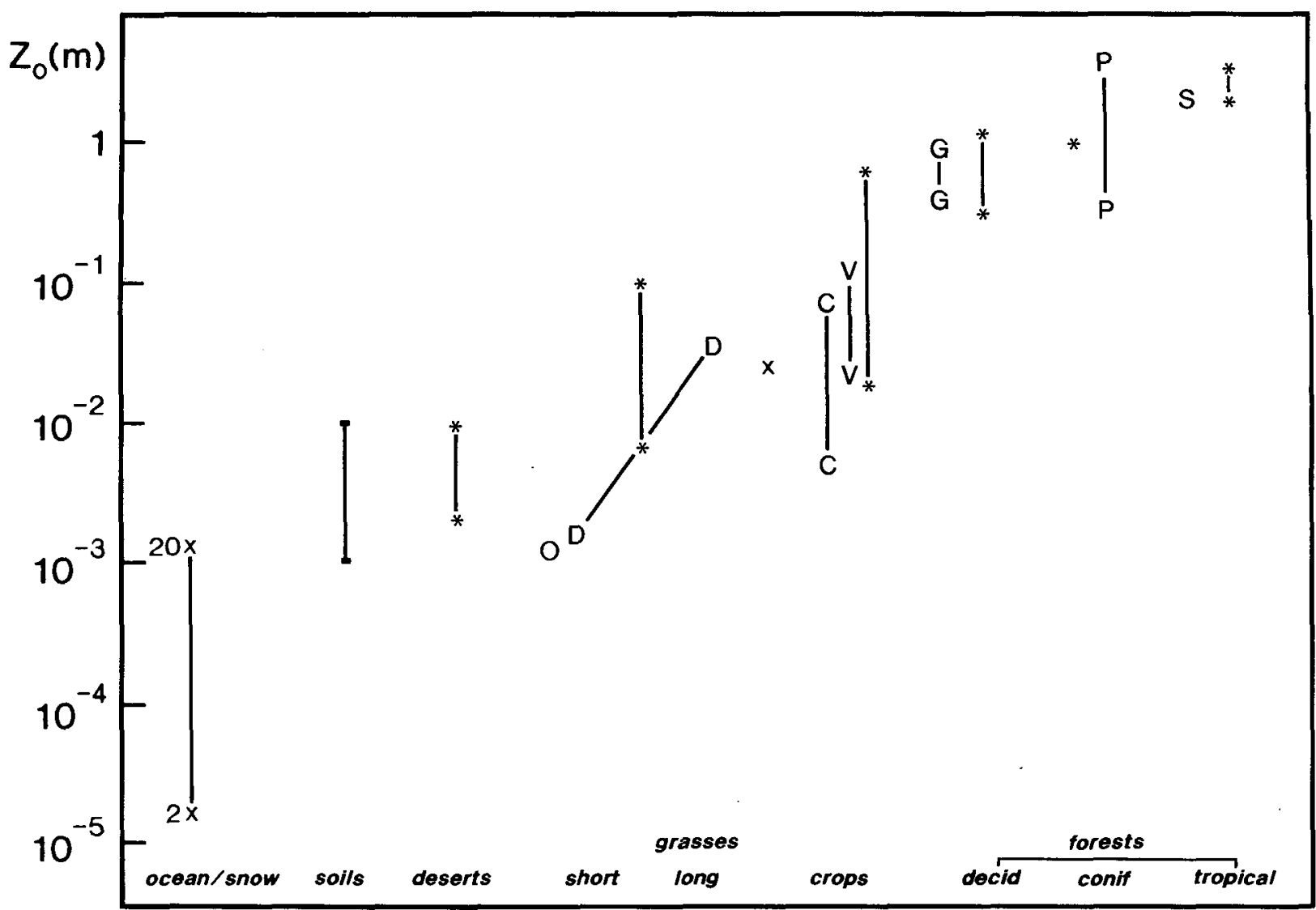

SURFACE

FIG. 2. Variation of surface roughness length with surface type, based on observations, literature values and model-specified values. Symbols as follows: (*) from Dorman and Sellers (1989) for some of their 12 surface types; $(X)$ from Garratt (1977) for the ocean (or blowing snow) for wind speeds (measured at $10-\mathrm{m}$ height) in the range $2-20 \mathrm{~m} \mathrm{~s}^{-1} ;(X)$ from Izumi (1971) for a wheat stubble; (G) from Garratt (1980) for subtropical savannah; (C) from Clarke et al. (1971) for a semiarid sparse grass cover; (V) from Hicks (1973) for a vineyard; (P) and (C) from Garratt (1992); (S) from Shuttleworth et al. (1984b) for a tropical rain forest; (D) from Deacon (1953), with the straight line representing the variation of $z_{0}$ with grass height.

required and for which significant research priorities already exist.

\section{Basic formulations for land-surface processes and the ABL used in GCMs}

\section{a. Surface fluxes}

Surface fluxes (stress $\tau$, sensible heat flux $H$, and evaporation $E$ ) are related to mean properties of the flow (wind speed $u$, virtual potential temperature $\theta_{v}$, and specific humidity $q$ ) through the use of drag and bulk transfer relations. These bulk relations are written,

$$
\begin{aligned}
\tau / \rho & =C_{D} u_{a}^{2}=u_{a} / r_{a M}, \\
H / \rho c_{p} & =C_{H} u_{a}\left(\theta_{0}-\theta_{v a}\right)=\left(\theta_{0}-\theta_{v a}\right) / r_{a H}, \\
E / \rho & =C_{E} u_{a}\left(q_{0}-q_{a}\right)=\left(q_{0}-q_{a}\right) / r_{a V}, \\
E_{p} / \rho & =C_{E} u_{a}\left(q_{0}^{*}-q_{a}\right)=\left(q_{0}^{*}-q_{a}\right) / r_{a V},
\end{aligned}
$$

where $E_{p}$ is the value of evaporation $(E)$ when the surface is saturated at temperature $T_{0}$. In Eqs. (1)-(4), $u_{a}$ (the wind speed), $\theta_{v a}$ (virtual potential temperature), and $q_{a}$ (specific humidity) are model variables at the lowest model level, and $\theta_{0}, q_{0}$ are surface values $\left[\theta_{0}\right.$ is the potential temperature associated with the absolute radiative temperature $T_{0}$; also $q_{0}^{*}=q^{*}\left(T_{0}\right)$ denotes the saturation specific humidity]. The aerodynamic resistances, $r_{a M}, r_{a H}$, and $r_{a V}$ for momentum, heat, and water vapor, respectively, are often used as an alternative to the transfer coefficients $C_{D}, C_{H}$, and $C_{E}$. The relations between resistances and transfer coefficients can be readily deduced from Eqs. (1) to (3).

In these equations, formulation of the bulk transfer coefficients depends on the reference level for the atmospheric variables $u_{a}, \theta_{v a}$, and $q_{a}$. If the lowest model level lies within the surface layer, the formulation is usually based on Monin-Obukhov similarity theory (Businger 1973), otherwise generalized boundary-layer 
similarity theory needs to be used (Arya 1977). To illustrate the influence of the aerodynamic roughness length $z_{0}$ upon the flux calculations, we can write the drag coefficient according to surface-layer (MoninObukhov) theory, as (appendix A)

$$
C_{D} / C_{D N}=\left(1-k^{-1} C_{D N}^{1 / 2} \Psi_{M}(\zeta)\right)^{-2}=F_{M}\left(z / z_{0}, \zeta\right)
$$

In Eq. (5), the von Karman constant $k=0.4, \zeta$ is a stability parameter $(\zeta=z / L$, where $L$ is a buoyancy length scale defined in terms of the surface fluxes), and the Monin-Obukhov function $\Psi_{M}(\zeta)$ is well known (see appendix $\mathrm{A}$ ). In addition, the heat transfer coefficient can be written (taking $C_{H}=C_{E}$ is a good approximation )

$$
C_{H} / C_{H N}=F_{H}\left(z / z_{0}, z / z_{T}, \zeta\right),
$$

where $z_{T}$ is a surface scaling length for temperature (see appendix A). In GCMs, it is usual to replace $\zeta$ (a parameter depending upon the fluxes) by a bulk Richardson number $\mathrm{Ri}_{B}$ (a parameter depending upon $u_{a}$ and $\theta_{v a}$ ). The neutral coefficients in Eqs. (5) and (6) are given by

$$
\begin{aligned}
& C_{D N}=k^{2} /\left(\ln \left(z / z_{0}\right)\right)^{2}, \\
& C_{H N}=k^{2} /\left(\ln \left(z / z_{0}\right) \cdot \ln \left(z / z_{T}\right)\right) .
\end{aligned}
$$

Values of $C_{D N} / C_{H N}$ and $z_{0} / z_{T}$ greater than unity reflect the more efficient transfer of momentum relative to heat and water vapor at rough surfaces. This situation exists in the natural world, and Fig. 3 summarizes results on the relative values of $z_{0}$ and $z_{T}$ (or $z_{q}$ for water vapor) for a range of natural and artificial surfaces. Much of the data relate to heat transfer over soil, grass, crops, and forest. For land surfaces generally, $\ln \left(z_{0} /\right.$ $z_{T}$ ) is almost independent of roughness Reynolds number $\left(\operatorname{Re}_{*}=u_{*} z_{0} / \nu\right.$, where $\nu$ is the kinematic viscosity of air), and for practical application can be taken as constant and equal to $2\left(z_{0} / z_{T}=7.4\right)$.

In the calculation of the sensible heat flux, the surface temperature is required and this is usually calculated by appeal to a surface energy balance equation (subsection 2b). For evaporation, either the surface humidity is evaluated by appeal to a suitable soil scheme, and Eq. (3) is used, or there is appeal to either the potential evaporation concept [Eq. (4)] or to the concept of surface resistance (subsection $2 \mathrm{e}$ ).

\section{b. Surface energy balance and surface temperature}

Calculation of the fluxes requires, inter alia, knowledge of the surface temperature. Determination of this is based on the surface energy balance (SEB), written as

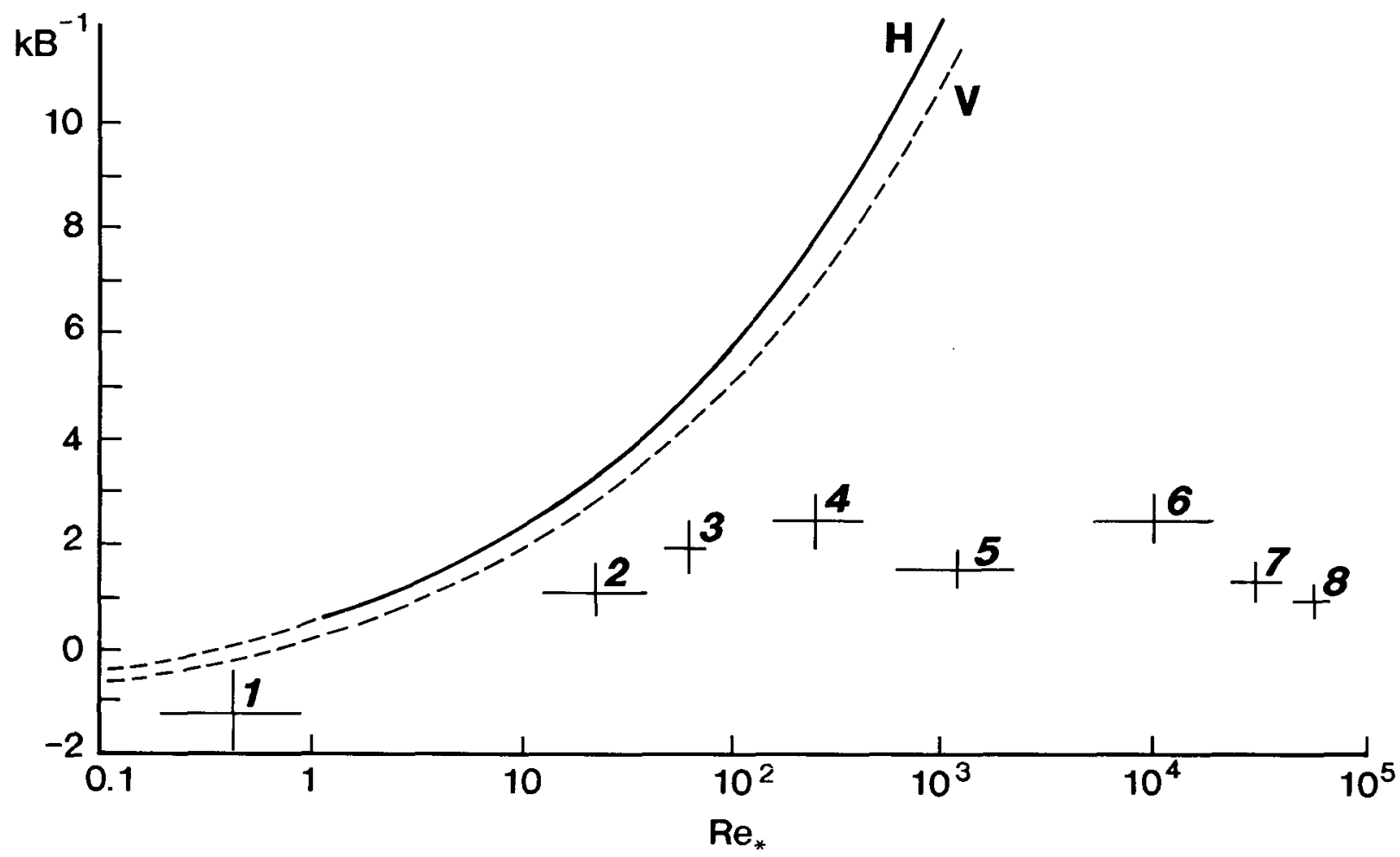

FIG. 3. Variation of $\mathrm{kB}^{-1}\left[=\ln \left(z_{0} / z_{T}\right)\right.$ or $\left.\ln \left(z_{0} / z_{q}\right)\right]$ with roughness Reynolds number $\mathrm{Re}_{*}$. Curves are based on laboratory data and represent heat $(H)$ and water vapor $(V)$ transfer. Atmospheric data (mainly for heat transfer) are also shown, based on data summarized in Garratt and Hicks (1973), Brutsaert (1982) and Garratt (1992). Surface types as follows: 1) Sea, 2) vineyard, 3) short grass, 4) medium grass, 5) bean crop, 6) savannah scrub, and 7) and 8) pine forests. 


$$
R_{N}-G_{0}=H+\lambda E,
$$

where $\lambda$ is the latent heat of vaporization, $R_{N}$ is the net radiative flux density to the surface (net radiation), and $G_{0}$ is the heat flux into the soil. The sum of the fluxes on the left-hand side of Eq. (9) defines the available energy. The flux $G_{0}$ is to be interpreted as the soil heat flux at the surface, and can be calculated from considerations of heat conduction and heat conservation in the soil.

Equation (9) contains the net radiation $R_{N}$, where

$$
R_{N}=R_{s}\left(1-\alpha_{s}\right)+\epsilon_{s} R_{L}^{d}+R_{L}^{u},
$$

with $R_{s}$ being the global shortwave radiative flux (positive), $R_{L}^{d}$ the downward longwave flux (positive), and $R_{L}^{u}$ the upward longwave flux (negative), all at the surface. In addition, $\alpha_{s}$ is the shortwave albedo of the surface and $\epsilon_{s}$ is its longwave emissivity.

Numerical models of the atmosphere usually compute the ground surface temperature $\left(T_{0}\right)$ from either Eq. (9) (a diagnostic form of the SEB equation) or from a prognostic form of this equation (e.g., Bhumralkar 1975; Deardorff 1978; Blackadar 1979; Carson $1982 \mathrm{~b}$ for details $)$. In the diagnostic case, ground heat flux may be parameterized very crudely-for example, as a constant fraction of $R_{N}$ or by assuming the heat capacity of the ground is zero and setting $G_{0}=0$. Alternatively, it may be computed using a full treatment of soil heat diffusion in a multilevel soil model (a number of GCMs do this, using three to four soil layers (e.g., see Warrilow et al. 1986; Blondin 1989: also the proposal in Abramopoulos et al. 1988).

In the prognostic case, $G_{0}$ is replaced by a soil storage term (proportional to $\partial T_{0} / \partial t$ ) and a subsurface soil heat flux $G_{1}$, which may be crudely parameterized or even set to zero (the so-called forcing method). One method that is used determines $G_{1}$ from a two-layer soil model (the so-called force-restore method, e.g., Deardorff 1978). In this, the surface temperature $T_{0}$ is approximated by the temperature of a thin upper layer of temperature $T_{s}$. The deeper soil layer is assumed to be of sufficient depth that over time scales of interest the flux of heat at the bottom is zero. The reader is referred to Dickinson (1988) for a more general application of the force-restore method.

\section{c. Surface humidity and soil moisture}

The level of soil moisture is closely linked with the evaporation from the soil surface and governed by the mass water balance in a surface layer of soil, depth $d$. For a unit area of surface, the balance can be written

$$
\rho_{w} d \partial \eta / \partial t=\rho_{w} P-E_{0}-F_{w d}-R+M_{s},
$$

where $\rho_{w}$ is the density of water, $\eta$ is the soil moisture content (units of volume per unit volume), $P$ is the precipitation rate (units of velocity), $F_{w d}$ is the flux of water across the base of the layer, $R$ is the runoff, and $M_{s}$ is snowmelt (all in $\mathrm{kg} \mathrm{m}^{-2} \mathrm{~s}^{-1}$ ).
In determining the surface humidity for a bare soil surface, two quite different approaches need to be identified-interactive and noninteractive. The noninteractive approach means that the surface humidity or soil wetness does not respond to atmospheric forcing in a realistic way, if at all. In the typical noninteractive scheme, the problem of computing $q_{0}$ (or the surface relative humidity $h_{0}$ ) for a bare soil in a model is bypassed by specifying some measure of the surface wetness. Thus, the actual evaporation is set to a constant fraction $(x)$ of the potential evaporation $E_{p}$, with $E_{p}$ defined by a bulk transfer relation [Eq. (4)].

It should be noted that $E_{P}$ can also be written in terms of the Penman-Monteith combination equation (e.g., Brutsaert 1982), written here as

$$
\lambda E_{p}=\Gamma\left(R_{N}-G_{0}\right)+(1-\Gamma) \rho \lambda \delta q_{a} / r_{a H},
$$

where $\Gamma=s /(s+\gamma), s$ is $\partial q^{*} / \partial T, \gamma$ is the psychrometric "constant" $\left(c_{p} / \lambda\right)$, and $\delta q_{a}$ is the humidity deficit in the air. In using Eq. (4) for a drying soil, a more practicable temperature is $T_{0 p}$, the temperature that the surface would have if it were actually wet, and $q$ and $T$ held constant. This hypothetical temperature is unknown, however, and the use of $T_{0}$ in Eq. (4) will result in unrealistically high values of $E_{p}$ when the surface is dry. The problem can be partly solved by using Eq. (12).

Many GCMs employ an interactive scheme with a realistic dependence of the evaporation upon soil moisture, but one which is less detailed than a multilevel soil model approach based on solution of the 1D moisture diffusion equations. Two examples are given here.

(i) Method 1 (bucket): The actual evaporation is a variable fraction $x$ of the potential evaporation, where $x$ is a specified function of the moisture content of a single (thick) soil layer (e.g., Manabe 1969). The main virtue of this approach is its simplicity, giving values of evaporation constrained between wet and dry limits. For time scales greater than a few days, drainage out through the bottom of the layer may become significant though it is often ignored or assumed to be part of the general runoff.

The main shortcoming of the bucket method is that the evaporation does not respond rapidly to short-period occurrences of precipitation, but rather changes the soil moisture and hence evaporation only gradually.

(ii) Method 2: The evaporation is made to depend upon the near-surface moisture content $\eta_{g}$, either through the variable fraction $x\left(\eta_{g}\right)$ (e.g., Deardorff $1977)$ or through a surface relative humidity $h_{0}\left(\eta_{g}\right)$ (e.g., Sellers et al. 1986; Hunt and Gordon 1989; Noilhan and Planton 1989). The soil moisture content can be calculated using a scheme comprising multiple soil layers, though in GCMs three layers seems to be the greatest used to date (e.g., Abramopoulos et al. 1988; Sellers et al. 1986). Whether a three-layer scheme, or a two-layer force-restore scheme (e.g., Deardorff 1977) 
is used, the model must represent both the rapid response of the near-surface moisture to forcing by precipitation or evaporation and also provide a source of moisture from the deep soil to the surface when there is no precipitation.

\section{d. Canopy parameterization}

The presence of vegetation over an area of ground modulates the evaporation from the soil, and contributes further to the vertical flux of water vapor into the ABL through transpiration. A realistic canopy formulation aims to represent the effects of vegetation (averaged over the grid square in a 3D numerical model) upon evaporation, energy partitioning, rainfall interception and soil moisture, as well as albedo and aerodynamic roughness. Inclusion of canopy effects allows the deep soil moisture (in the root zone) to act as a source for evapotranspiration. Except when completely wet, the canopy foliage will exert some degree of physiological control upon the evaporation rate, and the surface humidity becomes indeterminate. Under these conditions, a canopy or surface resistance is introduced into the evaporation formulation. The surface resistance concept is at the heart of most canopy models. For a canopy, this resistance is almost entirely determined by the stomatal resistance of the leaves and is given by

$$
r_{s t}=\rho\left(q^{*}\left(T_{0}\right)-q_{0}\right) / E \approx r_{s t}^{i} / L_{A},
$$

where $r_{s t}^{i}$ is the resistance of a single leaf and $L_{A}$ is the leaf area index. The resistance $r_{s t}$ is known as the bulk stomatal resistance. Equation (13) is commonly referred to as the "big-leaf" model, since it basically represents the whole canopy as a single hypothetical leaf of resistance $r_{s t}$. The surface resistance $r_{s}$ will be similar to $r_{s t}$ for a complete canopy cover, but will be different from $r_{s t}$ for partial cover. The resistance $r_{s}$ in the latter case would include effects of evaporation from the soil which contributes to the vertical flux above the canopy (e.g., Shuttleworth and Wallace 1985). Combination of Eqs. (3) and (13) allows the unknown $q_{0}$ to be eliminated and, with $r_{s t}$ replaced by $r_{s}$, yields

$$
E=\rho\left(q^{*}\left(T_{0}\right)-q_{a}\right) /\left(r_{a V}+r_{s}\right) .
$$

For closed canopies, where $E$ is predominantly transpiration, experimental results support the use of $r_{s t}$ in Eq. (14) (e.g., Perrier 1982). These show that $r_{s t}$ depends on several environmental factors, including incident solar radiation, air temperature, and soil moisture content, with a strong diurnal variation in its magnitude and variation between species. Single-level (big-leaf) canopy models, as opposed to the more complex multilevel canopy schemes, are most appropriate for use in mesoscale and general circulation models (e.g., Raupach and Finnigan 1988), and these will be emphasized here. GCMs, for example, can have the option of full canopy or bare-soil grid coverage.
For partial canopy cover, either as a sparse uniformly distributed cover or as full cover occupying only a fraction of the grid area, more complexity is involved.

For a complete vegetation cover, the simplest canopy model may use a constant $r_{s}$ in Eq. (14) for evaporation, with $r_{s}$ values consistent with known bulk stomatal resistances (e.g., as used in earlier versions of the UKMO GCM; Carson 1986). In contrast, quite sophisticated treatments for the surface resistance may be used, as found in relatively complex canopy models such as SiB (Sellers et al. 1986), used in experimental versions of several GCMs now (e.g., NMC and GLA models; Sato et al. 1989a, Sud et al. 1990, respectively); and BATS (Dickinson et al. 1986), used in experimental versions of the NCAR GCM (e.g., Dickinson and Henderson-Sellers 1988), BEST (Pitman et al. 1991), and in simpler canopy models (e.g., Noilhan and Planton 1989).

Numerous formulations that purport to represent the dependence of the stomatal resistance upon a number of factors, including soil moisture availability, solar radiation, absolute temperature, atmospheric water vapor deficit, and carbon-dioxide concentration exist. The bulk stomatal resistance is usually written in general functional form as (Jarvis 1976)

$$
r_{s}=r_{s}^{*} F_{1} F_{2} F_{3} F_{4} F_{5},
$$

where $r_{s}^{*}$ is an unconstrained daytime resistance. It typically has values of $50 \mathrm{~s} \mathrm{~m}^{-1}$ for moderately dense forests. In Eq. (15), $F_{1}$ gives the radiation dependence, $F_{2}$ gives the soil moisture dependence (water stress), $F_{3}$ gives the vapor pressure deficit dependence, $F_{4}$ gives the temperature dependence, and $F_{5}$ gives the $\mathrm{CO}_{2}$ dependence. Detailed expressions for the functional forms for each of $F_{1}$ to $F_{5}$ are beyond the scope of this paper (but see, e.g., Dickinson et al. 1986; Sellers et al. 1986; Noilhan and Planton 1989). Figure 4 summarizes both daytime minimum values of $r_{s}$ (mainly from observations) and values of $r_{s}^{*}$, noting that the larger values of minimum $r_{s}$ are to be expected since they include the effects of radiation and soil moisture through functions $F_{1}$ and $F_{2}$ (both greater than one). The scatter in the diagram reflects, to some extent, the difficulty of measuring representative values of stomatal resistance for the canopy as a whole. It needs stating that all bulk stomatal resistance formulations are based on small-scale field observations and that the resistance schemes previously described need continuing evaluation for application in the large-scale modeling context (see e.g., Jarvis and McNaughton 1986). In practice, use of Eq. (15) in a canopy scheme embedded within a GCM provides the correct limits for evaporation: potential evaporation when the canopy is wet $\left(r_{s}=0\right)$ and negligible evapotranspiration when the soil is dry. It also gives a diurnal and seasonal cycle in resistance, and hence evaporation, that approximates the observed behavior in many situations, mainly because the functional forms are empirically based. 

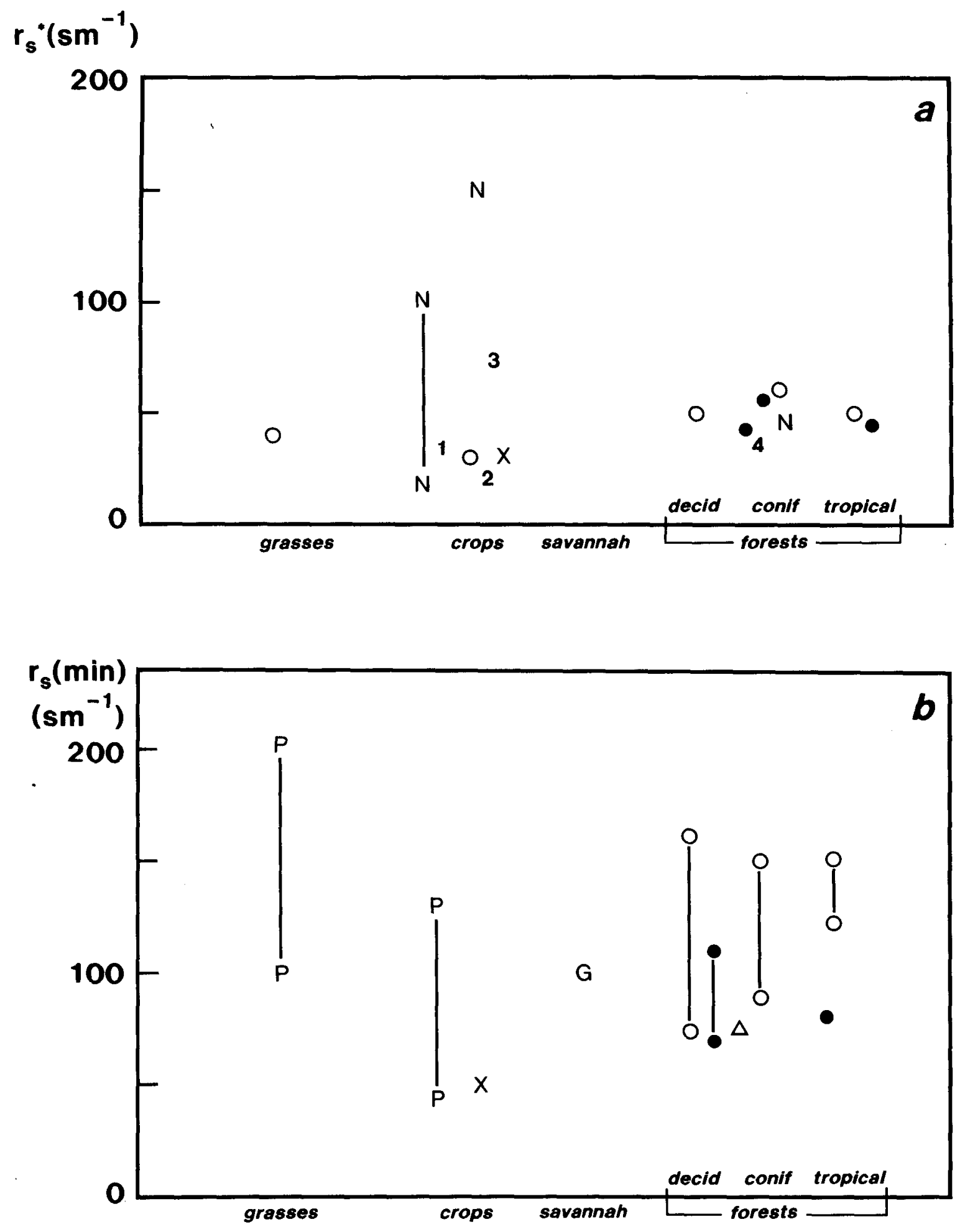

FIG. 4. Variation of unconstrained stomatal resistance $r_{s}^{*}$ and minimum surface resistance $r_{s}(\min )$ with vegetation type, based on observations, literature values and model-specified values. Symbols are as follows: (a) (O) from Dorman and Sellers (1989); $(\bullet)$ from Shuttleworth et al. (1984b) for 3 forest sites; $(X)$ from Sellers and Dorman (1987) for barley; (N) from Noilhan and Planton (1989) for maize (showing a wide range in resistance), oats (anomalously high) and a pine forest; 1) barley, 2) wheat, 3) maize, 4) spruce forest are all from Sellers and Dorman (1987). (b) (O) from Dorman and Sellers (1989); (•) from Shuttleworth et al. (1984b); $(\times)$ from Sellers and Dorman (1987) for maize; $(\triangle)$ from Sellers and Dorman (1987) for spruce; (G) from Garratt (1978) for subtropical savannah; (P) from Perrier (1982). 
Simple, but realistic, canopy models are formulated either as an isothermal system (e.g., Noilhan and Planton 1989), with both canopy and upper-soil layers at the same temperature, or as a nonisothermal system (Deardorff 1978; Dickinson et al. 1986; Sellers et al. 1986; Pitman et al. 1991), where the canopy and soil temperatures are predicted separately. These models are essentially $1 \mathrm{D}$ formulations applied to a grid area that might comprise either uniform cover (soil or vegetation) or specified fractions of bare soil and full canopy.

In all schemes, the main task is to compute the turbulent fluxes of heat and water vapor, $H_{0}$ and $\lambda E_{0}$, respectively, from the surface (canopy and soil) to the air above. Models such as SiB and BATS involve detailed formulations for evaluating component fluxes from the soil beneath the canopy, from open areas between the canopy elements, as well as from the foliage itself. In contrast, the model of Noilhan and Planton (1989) used in experimental versions of the CNRM GCM in France does not predict soil fluxes beneath the vegetation, but rather soil and atmospheric fluxes are calculated for open (unvegetated) areas with canopy fluxes calculated for the vegetated areas. In all cases, the component fluxes are averaged over the grid area in some ad hoc manner, with the fluxes weighted according to the fractional extent (as specified) of each surface type.

For illustration of the main principles involved, we introduce a set of basic equations required to carry out this task; this set is the foundation of several schemes discussed in the literature (e.g., Deardorff 1978; Dickinson et al. 1986; Sellers et al. 1986; Noilhan and Planton 1989) and is similar to the simplified SiB model described by Xue et al. (1991).

Figure 5 sketches the main elements of this approach, which assumes a two-layer soil system. A foliage temperature $\left(T_{f}\right)$ and surface soil temperature $\left(T_{g}\right)$ are calculated, based on the surface-energy balance equation applied to the canopy layer and to the upper thin soil layer. This gives,

$$
\begin{aligned}
& C_{f} \partial T_{f} / \partial t=R_{N f}-H_{f}-\lambda E_{f}, \\
& C_{g} \partial T_{g} / \partial t=R_{N g}-H_{g}-\lambda E_{g}-\gamma_{g}\left(T_{g}-\bar{T}\right),
\end{aligned}
$$

where $C_{f}, C_{g}$ are specified or calculated heat capacities per unit area for foliage and soil, respectively. It is worth noting that the heat capacity of a stand of vegetation is typically much smaller than that of soil, in the range $0.1-1 \mathrm{~mm}$ of water equivalent per unit leaf area index $\left(L_{A}\right)$ (say, $C_{f} \approx 2000$ to $20000 \mathrm{~J} \mathrm{~m}^{-2} \mathrm{~K}^{-1}$ for $L_{A}$ $=5$, representing crops and forests) compared with $15-60 \mathrm{~mm}$ of water for soils $\left(C_{g} \approx 7 \times 10^{4}\right.$ to 2.5 $\times 10^{5} \mathrm{~J} \mathrm{~m}^{-2} \mathrm{~K}^{-1}$ for dry sand and wet clay).

The deep soil temperature $\bar{T}$ is calculated from

$$
C_{g}^{\prime} \partial \bar{T} / \partial t=R_{N g}-H_{g}-\lambda E_{g},
$$

where the heat capacity $C_{g}^{\prime}$ is usually calculated for a

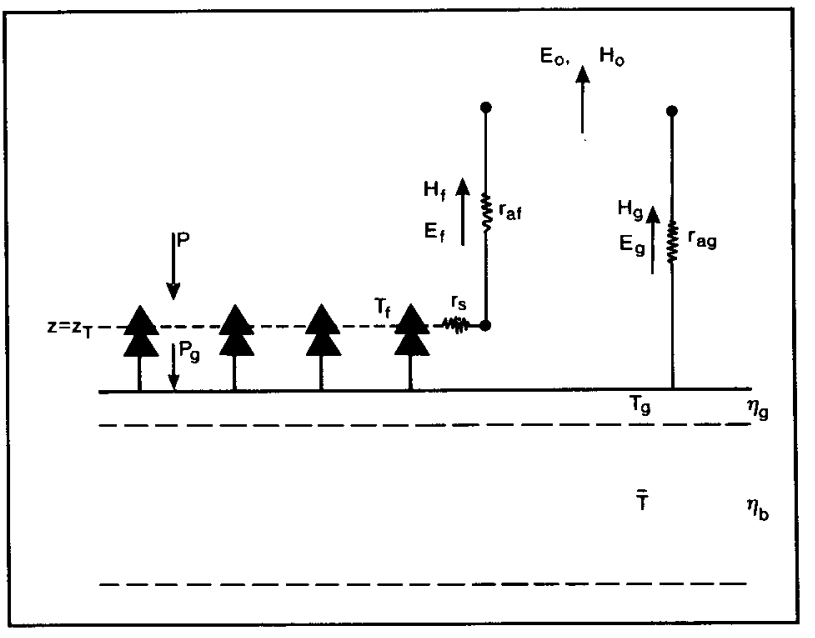

FIG. 5. Schematic representation of the main elements of a canopy model; this simplified version neglects subcanopy fluxes. Linked to both the atmosphere (via resistances $r_{s}$ and $r_{a}$ ) and the deep soil (via evapotranspiration ), the canopy and upper soil layer are assumed to be at temperatures $T_{f}$ and $T_{g}$, respectively. $P_{g}$ is the precipitation reaching the soil surface under the canopy. If $A B L-a v e r a g e d$, or ABLtop properties, are to be used in place of surface-layer properties, $r_{a}$ is replaced by a boundary-layer resistance. Component fluxes are shown from the canopy and from open soil; $H_{0}$ and $E_{0}$ are the gridaveraged fluxes. Definitions of all other variables can be found in the text.

soil layer of depth $\approx 1 \mathrm{~m}$. The sensible heat fluxes are then calculated from

$$
\begin{aligned}
& H_{f}=\rho c_{p}\left(T_{f}-T_{a}\right) / r_{a H f}, \\
& H_{g}=\rho c_{p}\left(T_{g}-T_{a}\right) / r_{a H g},
\end{aligned}
$$

where $r_{a H g}$ and $r_{a H f}$ are aerodynamic resistances for heat transfer. In Eqs. (19) and (20), $T_{a}$ is the temperature at the first model level. Two treatments of the flux relations (valid both for the sensible and latent heat fluxes) need to be distinguished. In the first case, where heat fluxes between soil and foliage beneath the canopy are neglected [e.g., as in the scheme of Noilhan and Planton (1989) illustrated in Fig. (5)] $r_{a H g}$ and $r_{a H f}$ are straightforward, and can be evaluated using Monin-Obukhov theory (section 2a and appendix A), with heat transfer coefficients dependent upon $z_{0}$ and $z_{T}$. In effect, each represents the resistance between the level $z=z_{T}$ for soil or canopy and the first model level. In the second case, where the subcanopy heat fluxes are not ignored (e.g., as in SiB and BATS), it is usual to write Eqs. (19) and (20) in terms of a canopy air temperature. When written as above, $r_{a H g}$ and $r_{a H f}$ become functions of several resistances, including a soilcanopy air resistance and a bulk-canopy laminar boundary-layer resistance (these correspond to transfer between soil and canopy air, and foliage and canopy air, respectively). Consequently, the heat flux $H_{g}$ becomes the sum of a flux from open soil areas and a flux from beneath the canopy. 
For evaporation calculations, soil moisture is required, usually through a two- or three-layer soil scheme. In the case of the two-layer scheme, a thin surface layer (moisture content $\eta_{g}$ ) and a deeper reservoir layer (moisture content $\eta_{b}$ ) are represented (Deardorff 1977), with

$$
\begin{aligned}
& \partial \eta_{g} / \partial t=a_{0}\left(P-E_{g} / \rho_{w}\right)-b_{0}\left(\eta_{g}-\eta_{e q}\right), \\
& \partial \eta_{b} / \partial t=c_{0}\left(\eta_{g}-\eta_{e q}\right)-E_{d c} / \rho_{w}
\end{aligned}
$$

where

$$
\eta_{e q}=\eta_{b}-f\left(\eta_{b} \text {, soil type }\right) .
$$

Here, the restore term of Eq. (21) takes account of the effects of gravity by incorporating a moisture variable $\eta_{e q}$ in place of $\eta_{b}$, the deep soil moisture content (see Noilhan and Planton 1989). The variable $\eta_{e q}$ represents an equilibrium moisture content where the force of gravity balances capillary forces. It is possible for the equilibrium values to be significantly lower than the mean moisture, particularly for coarse grained soils such as sand. Note also that we have included in Eq. (22) a canopy transpiration rate equal to the dry-canopy evaporation $E_{d c}$, which is set to zero for a baresoil surface. The function $f$ can be given in tabular form, based on the curves given in Noilhan and Planton (1989), for example. The coefficients $a_{0}, b_{0}$, and $c_{0}$ need to be derived for each soil type over a wide range of $\eta_{g}$ and $\eta_{b}$ values.

With $\eta_{g}$ determined, the soil evaporation is found from either,

$$
E_{g} / \rho=\left(h_{0}\left(\eta_{g}\right) q^{*}\left(T_{g}\right)-q_{a}\right) / r_{a V g},
$$

or from

$$
E_{g}=x\left(\eta_{g}\right) E_{P} .
$$

In the latter, $E_{P}$ is given by either Eq. (4) or Eq. (12). The functions $x\left(\eta_{g}\right)$ can be readily found from onedimensional numerical simulations, based on the averaged properties of real homogeneous soils, or from observations related to specific soil types (e.g., Mahrt and Pan 1984).

In the case of foliage evaporation, a distinction needs to be made between dry and wet canopies. Thus, for a wet canopy, evaporation $\left(E_{w c}\right)$ is at the potential rate, so that

$$
E_{w c}=\rho\left(q^{*}\left(T_{f}\right)-q_{a}\right) / r_{a v f},
$$

while for a dry canopy, with evapotranspiration under physiological control, evaporation $\left(E_{d c}\right)$ is given by

$$
E_{d c}=\rho\left(q^{*}\left(T_{f}\right)-q_{a}\right) /\left(r_{a V f}+r_{s}\right) .
$$

The partitioning of the canopy evaporation between dry and wet components is made to depend on the amount of liquid water residing on the foliage, due either to rainfall or dewfall. In addition, soil moisture depends on precipitation reaching the ground, therefore the effects of canopy interception of rainfall should be included. This is done by carrying an equation for $m$, the depth of water residing on the foliage. This can be written

$$
\partial m / \partial t=P-E_{w c} / \rho_{w}-P_{g},
$$

where $P$ is precipitation at the top of the canopy and $P_{g}$ is the runoff from the interception reservoir, dependent upon the canopy interception of rain. In some schemes (e.g., Sellers et al. 1986), allowance is made for attenuation through the canopy of intercepted rainfall and an attenuation factor is included in the first term on the rhs of Eq. (28). When $m$ reaches $m^{+}$, the maximum depth of water that can reside on the foliage, rain will no longer be intercepted but can reach the ground as throughfall. When the precipitation falls as snow, the treatment is somewhat different. Snow accumulation and snow melting must be accounted for, the surface albedo is modified (so might be the roughness), and the interception of snow by vegetation requires a new approach. A detailed discussion on the treatment of snow is beyond the scope of the present paper, but can be found, for example, in Holloway and Manabe (1971), Carson (1982b), and Blondin (1989).

As an aside, it is worth noting that in general circulation models, for example, where grid scales may be hundreds of kilometers, some account of spatial variability in rainfall interception is made. The simplest approach is as follows: when $m<m^{+}$, it is assumed that only a fraction $\mathrm{m} / \mathrm{m}^{+}$of the canopy is wetted. The evaporation from the canopy, averaged over the whole grid area, is then given by

$$
E_{f}=\left(m / m^{+}\right) E_{w c}+\left(1-m / m^{+}\right) E_{d c},
$$

while if condensation is occurring through dewfall with $E_{w c}<0, E_{f}$ is set equal to $E_{w c}$; that is, the whole canopy is assumed moistened. The spatial variability of rainfall over a grid area (accounting, for example, for $x \mathrm{~mm}$ $\mathrm{hr}^{-1}$ in the form of either steady, widespread rain or isolated heavy-convective rain over a small fraction of the grid area) has been introduced into the UKMO GCM (Warrilow et al. 1986), and the problem of how to model this in more detail has recently received some attention by Pitman et al. (1990). They used BATS in a stand-alone mode (uncoupled from a GCM), and computed surface runoff $(R)$ and canopy drip $\left(P_{g}\right)$ by assuming that the local precipitation rate (over a fraction of the grid area) was described by a decaying exponential probability distribution.

In the foregoing equations, specification of $r_{s}$ is quite crucial to the evaluation of evapotranspiration $E_{d c}$, and $\mathrm{m}^{+}$also needs to be set. For full canopy cover, both can be expected to depend on foliage density and hence upon leaf area index. In the case of the maximum canopy interception, a simple relation that covers a range of grasses, crops, and tree species is

$$
m^{+} \approx a_{1} L_{A},
$$


with $\mathrm{m}^{+}$in millimeters of water. No distinction is made in Eq. (30) between the leaf area index and the total projected area index for leaves and stems (see e.g., Dickinson 1984). Deardorff (1978) gave $a_{1}=1 / 7$ for a wheat crop, while Dickinson (1984) suggested taking $a_{1}=0.2$ for general application. Using the latter value, typical values of $\mathrm{m}^{+}$are $1 \mathrm{~mm}$ for a thick green canopy, suggesting that it would take approximately two hours for the foliage to become fully saturated from a dry state, at a rainfall rate of $0.5 \mathrm{~mm} \mathrm{~h}^{-1}$ with no evaporation from the leaves.

Finally, the grid-average sensible and latent heat fluxes are calculated from relations of the type

$$
\begin{gathered}
H_{0}=\sigma_{f} H_{f}+\left(1-\sigma_{f}\right) H_{g}, \\
E_{0}=\sigma_{f} E_{f}+\left(1-\sigma_{f}\right) E_{g} .
\end{gathered}
$$

Here, the canopy fraction $\sigma_{f}$ appears explicitly, though in many formulations (e.g., Deardorff 1978; Sellers et al. 1986) it is absorbed into the parameterization of the component fluxes.

The foregoing formulations deal with the heat fluxes. Calculation of the surface stress [Eq. (1)] or friction velocity [Eq. (A1)] is also required in a GCM and, in analogy with Eqs. (31) and (32), can be written as contributions from soil and foliage, with

$$
\tau_{0}=\sigma_{f} \tau_{f}+\left(1-\sigma_{f}\right) \tau_{g},
$$

where

$$
\tau_{f}=\rho u_{a} / r_{a M f} \text { and } \tau_{g}=\rho u_{a} / r_{a M g} .
$$

For all the surface fluxes, the aerodynamic resistances are functions of stability, with $z / L$ or $\mathrm{Ri}_{B}$ being calculated separately for foliage and bare soil.

\section{e. The atmospheric boundary layer}

Calculation of the surface fluxes is one of the most important components of a boundary-layer parameterization scheme in a large-scale model. In addition, it is usually necessary to evaluate the following:

(i) The depth $h$ of the ABL, in order that momentum, heat, and water vapor can be distributed vertically.

(ii) The values of the turbulent fluxes and other turbulent properties within the ABL, in order that the vertical flux divergence can be calculated, or the turbulent (entrainment) fluxes at the top of the ABL. In slab models of the ABL, prognostic variables are averaged throughout the $\mathrm{ABL}$, with their calculation requiring knowledge of the fluxes at the surface and $\mathrm{ABL}$ top, together with the ABL depth itself.

(iii) The development, maintenance, and dissipation of ABL clouds.

\section{1) RATE EQUATION FOR ABL DEPTH}

For the clear convective boundary layer over land, an elaborate form of growth equation was developed by Deardorff (1974) for use in atmospheric models. For the stable or nocturnal situation, growth rates are much smaller than in the convective case, and a diagnostic form for the depth may suffice. For example, the equilibrium depth of the nocturnal boundary layer as given by the Zilitinkevich (1972) relation could be used. Alternatively, the rate equations described by Nieuwstadt and Tennekes (1981) and Yamada (1979) can be used to give the evolution of the nocturnal ABL depth.

None of the approaches just mentioned is strictly valid for the cloud-topped boundary layer except perhaps for the case of lightly scattered shallow cumulus clouds. In the case of the near-neutral or convective cloudy ABL, the effects of liquid water on buoyancy, and of radiative cooling on entrainment, need to be taken into account. Rate equations for the stratocumulus-topped mixed layer have been discussed in detail by, for example, Deardorff (1976). If a rough estimate of the $\mathrm{ABL}$ depth is required when $\mathrm{ABL}$ cloud is predicted, the level of the lowest major elevated inversion (or the level of the subsidence inversion) can be taken as the ABL top.

\section{2) TURBULENCE CLOSURE SCHEMES}

The principal aim of such a scheme is to allow calculation of vertical fluxes throughout the turbulent $\mathrm{ABL}$, covering the whole range of stabilities. Options available include the first-order closure approach, often referred to as $K$-closure ( $K$ is an eddy diffusivity) and common in many GCMs (see Table A1), and higherorder schemes, usually one-and-one-half order (e.g., as used in the UCLA/CSU GCM) or second-order (e.g., as used in the GFDL II GCM). $K$ theory is likely to fail in the convective $\mathrm{ABL}$ during strongly buoyant conditions where length scales of the energy containing eddies are comparable with the depth of the layer over which transfer is occurring. Some schemes in largescale models use a modified $K$ approach to allow for countergradient fluxes and avoid the use of negative $K$. The reader is referred to Louis (1979), Andre (1983), Sommeria (1988), and Stull (1988) for details of $K$ schemes.

Second-order closure avoids the need to parameterize the fluxes using $K$ coefficients. The reader is referred to Mellor and Yamada $(1974,1982)$ for details.

\section{3) ABL CLOUD PARAMETERIZATION}

In many $\mathrm{ABL}$ and larger-scale models, $\mathrm{ABL}$ layered cloud is assumed to exist if the ABL top lies above the local condensation level, that is, if the relative humidity at the ABL top is $100 \%$. In many GCMs, low-level stratiform clouds are assumed to be present when the gridpoint relative humidity at a specified level in the model exceeds some critical value (typically $85 \%-$ 95\%). Between this critical value and saturation, fractional cloudiness is allowed to increase according to 
some empirical relation (e.g., a quadratic relation), attaining full cover at $100 \%$ relative humidity. Some schemes then introduce a dependence of cloudiness upon other variables, for example, (i) low-level stability; (ii) the cloud-top entrainment instability (see e.g., Randall et al. 1985; Slingo et al. 1989).

In both slab and high-resolution ABL models, incorporation of moist thermodynamic equations allows the presence of cloud to interact both with the radiation and turbulence fields, and to affect both the surface energy balance, for example, and the depth of the ABL.

In many GCMs in use today, the depth of the ABL is not governed by any suitable rate equation and may not even be computed (although it may be set equal to a fixed value). The presence of stratiform cloud is then unaffected by boundary-layer dynamics. Such a noninteractive system can never aspire to simulate the real-world behavior and distribution of boundary-layer cloud.

Because the ABL controls the evaporation and turbulent redistribution of water substance into the atmosphere, it strongly determines the global distribution of both cumuliform and stratiform clouds. A comprehensive parameterization of $\mathrm{ABL}$ processes for a numerical model of the atmospheric circulation must take into account the interaction of the $\mathrm{ABL}$ with clouds. This aspect of the ABL parameterization problem has an importance comparable to that of determining the turbulent fluxes.

\section{Main GCMs}

The studies reviewed by Mintz (1984) and Rowntree (1988) involved GCMs in use up to the early 1980s. Many, but certainly not all, are more sophisticated in their ABL and land-surface representation today compared with 10 years ago; however, there is a need to distinguish between operational versions of a GCM and experimental versions. Thus, the latter may be used for many years to aid the development of new formulations, but in practice an older, well-tuned (operational) version will be used for many of the climate simulations. It is not necessarily accurate to say, for example, that the NCAR climate model (GCM) has a detailed canopy scheme (BATS) as part of its structure. One version of the NCAR model can be run with BATS, but this is not yet an integral part of the standard, operational GCM.

For the purposes of this review, and of a World Climate Research Programme workshop held in Reading, UK in August 1988, many GCM groups were contacted for information related to contemporary model structure. Formal publications do exist for most GCMs, but these are usually many years old and may not accurately represent the current GCM structure. On the other hand, latest technical reports are often misleading, in that details of model schemes refer to experimental model versions only. We have attempted to summarize the situation in respect to a range of GCMs in use around the world, many involved in the study of climate and climate change (see also, Cess et al. 1989, 1990; Boer et al. 1991; and Randall et al. 1992 for summaries from a different viewpoint of up to 19 GCMs used in cloud, climate, and surface energy flux intercomparisons). Unfortunately, most GCMs have not been used in extensive sensitivity studies (see later Tables 4, 5, and 6).

The relevant details are summarized in appendix $B$. From the ABL and land-surface perspective, models have many common features, major amongst these being the improved soil moisture schemes (new GLA and UCLA/CSU models), canopy schemes (UKMO, new GLA, new NMC, and UCLA/CSU models), multilevel soil temperature schemes (UKMO model), slab ABL (old GLA and UCLA/CSU models), turbulence closure scheme (GFDL II and new GLA models), and an interactive stratocumulus cloud scheme (UCLA/CSU model).

Much of the material described in section 2 serves as the basis for existing or planned physical parameterization schemes in numerical models of the atmosphere. The following comments (with reference to the details in appendix B) indicate the degree to which GCMs have incorporated aspects of land-surface and ABL descriptions.

\section{a. Surface}

(i) Most GCMs allow $C_{d}$ or $z_{0}$ to vary geographically, even though detailed datasets on vegetation distribution have been available since the early 1980s. All models distinguish between land, sea, and ice surfaces.

(ii) Most GCMs determine the transfer coefficients from surface-layer theory, with a few using ABL theory (e.g., based on Deardorff 1972) appropriate to a slab ABL.

(iii) All operational GCMs have $C_{H}=C_{E}$, and $z_{0}$ $=z_{T}$.

(iv) Few GCMs account for subgrid orography, even in a crude way.

(v) Few GCMs take account of averaging effects (subgrid variability).

(vi) Most GCMs set $x=\eta / \eta_{k}$, for $\eta<\eta_{k}$, and $x$ $=1$ for $\eta>\eta_{k}$ in Eq. (25), where $\eta$ is the amount of water either in a bucket, or in a thick/thin soil layer with a deeper reservoir. In an increasing number of GCMs, a distinction is now made between soil types, and surface parameters are allowed to vary geographically. Only a few models currently allow for the control of vegetation on evaporation. In its simplest form, this involves setting $x=\left(1+r_{s} / r_{a}\right)^{-1}$ with $r_{s}$ and $r_{a}$ being a surface and aerodynamic resistance, respectively. There are now very detailed surface/canopy schemes available (e.g., Dickinson et al. 1986; Sellers et al. 1986), but to date few operátional GCMs use them consistently and extensively. 
(vii) Surface temperature is evaluated in one of several ways, all based on the surface energy balance equation,

(a) Prognostically, with $G_{0}$ replaced by $\partial T_{0} / \partial t$ (the forcing method).

(b) As in (a), with $G_{0}$ replaced by $\partial T_{0} / \partial t+G_{1}$ (force-restore method).

(c) Iteratively, with $G_{0}$ evaluated from a soil model (or set to zero).

(viii) All GCMs allow the albedo $\alpha_{s}$ to vary geographically, and to vary seasonally with snow cover (see Table 1 for data sources).

(ix) For the sea $E=E_{P}$, and all models make allowance for the presence of sea ice, in terms of the albedo and roughness specification. The roughness length over the sea is either taken as constant (as im-

TABLE 1. Datasets.

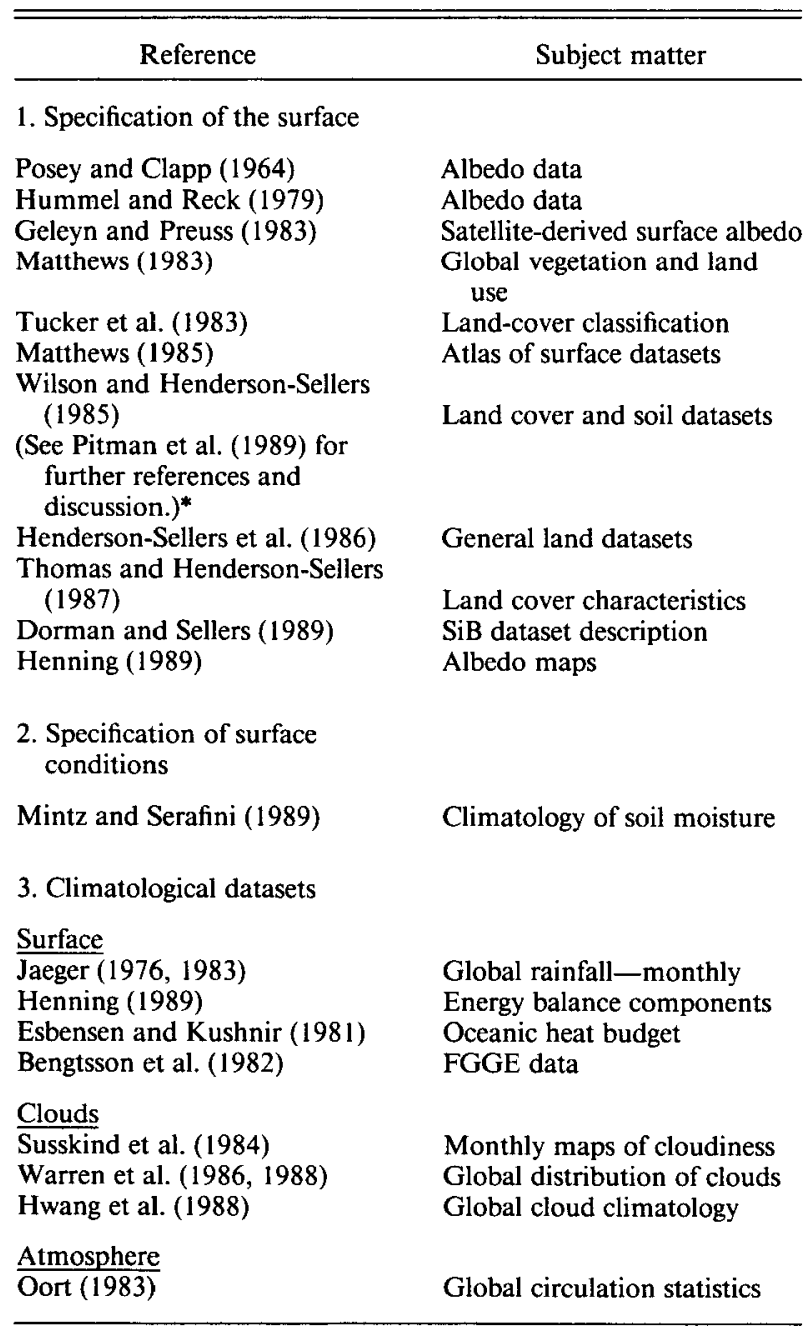

* See Smith and Warrilow (1989) and Warrilow and Buckley (1989) for a discussion on the reduction of data from the sets of Wilson and Henderson-Sellers (1985). plied in assuming a constant drag coefficient), or set to vary according to the Charnock relation

$$
z_{0}=\alpha_{c} u_{*}^{2} / g \text {. }
$$

The most appropriate value of $\alpha_{c}$ is about 0.017 (Garratt 1977; Wu 1982) though many models use substantially higher values (based on Clarke 1970).

\section{b. $A B L$}

(i) Most GCMs do not predict the ABL depth, and thus do not link ABL growth with cumulus development (exceptions are the new GLA GCM and UCLAbased GCMs).

(ii) Most GCMs have only one to four levels below 1-2 $\mathrm{km}$ and thus within the daytime ABL.

(iii) Most GCMs represent the vertical fluxes as

$$
F_{s}=-K \partial s / \partial z \text {, }
$$

with $K$ determined from a simple mixing-length relation usually with a stability dependence. This then allows the flux divergence $\left(\partial F_{s} / \partial z\right)$ to be evaluated at each model level, with the ABL top indicated as the level where $K$ first reaches a specified small value. Alternatively, the flux divergence term can be approximated as $F_{0} / h$, where the ABL depth $h$ must be evaluated (it is specified in many models). This approximation effectively uniformly mixes the property through the layer of depth $h$, and in several models the $\mathrm{ABL}$ is represented as a slab of atmosphere with a variable first-model level coinciding with the ABL top.

(v) Few GCMs link the presence of low-level stratus and stratocumulus with $\mathrm{ABL}$ mixing and entrainment.

(vi) Most GCMs now have a diurnal cycle (probably all have this as an option).

\section{Datasets}

Specialized datasets may be required for three main purposes: (i) specification of the lower-boundary conditions; (ii) specification of initial conditions, and (iii) for comparison with numerical model output. In the first case, we are looking at datasets that allow the soil/ vegetation type, the albedo, the aerodynamic roughness, and the mean height of the orography to be specified as a function of geographical location. In the second case, climatological variables may be available to initialize a model integration-these may be in the form of mean monthly atmospheric variables as a function of height and location, or of surface variables as a function of season and location. In general, accurate initialization of a climate model is not a major requirement, and therefore quite different to the needs of numerical weather prediction models. Nevertheless, a realistic initialization of the soil moisture field, for example, may be required for climate simulations (e.g., see Mintz and Serafini 1989). In the third case, validation of model simulations depends on the availability 
of observations, suitably reduced and averaged, for comparison with model output. Observations might take the form of time-averaged atmospheric fields of velocity, temperature, and humidity; surface fields of pressure, fluxes, and precipitation; climatological fields of clouds; and detailed data on the diurnal behavior of surface variables at specific locations.

Table 1 summarizes the types of datasets available, with suitable references. The data contained therein are used extensively in the validation of model-simulated climate. Perrier (1982) should be consulted for an earlier discussion on datasets useful for both the validation of models and the suitability for specifying lower-boundary conditions. The table does not include specialist datasets on the surface layer or ABL, which are usually based on point measurements. The reader's attention should be drawn to the HAPEX dataset, available on request from the French group of MeteoFrance (Andre et al. 1986, 1990), and Henning's (1989) atlas of the surface heat balance of the conti- nents. Both are invaluable for the assessment of model simulations related to the mean diurnal cycle of surface fluxes and the regional surface energy balance over continents.

\section{Main sensitivity results_Land surface \\ a. Albedo and soil moisture}

In the last 15 years evidence has been accumulating from numerical model studies that the climate is sensitive to variations in processes and parameters at the earth's surface. The experiments of Charney et al. (1977) demonstrated such sensitivity to surface albedo and the parameterization of evaporation. These experiments, and several reviewed by Mintz (1984), used relatively simple parameterization schemes and most surface characteristics lacked geographical variation. More complex, and hopefully realistic, schemes have been developed in recent years, both regarding geographical variations in parameters such as albedo and

TABLE 2. Sensitivity studies involving surface albedo and surface moisture changes. SM1 and SM2 denote noninteractive and interactive soil moisture schemes. The abbreviations $R$ and $G$ refer to either regional $(R)$ or global $(G)$ climate impact investigations. In the last column, we abbreviate day (d), week (w), month (mon), and year (y).

\begin{tabular}{|c|c|c|c|c|}
\hline Reference & Model & Comment & $\mathrm{R} / \mathrm{G}$ & $\begin{array}{l}\text { Integration } \\
\text { time/averages }\end{array}$ \\
\hline \multicolumn{5}{|l|}{ 1. Surface albedo } \\
\hline $\begin{array}{l}\text { Charney et al. (1977) } \\
\text { Chervin (1979) } \\
\text { Carson and Sangster (1981) } \\
\text { Sud and Fennessey (1982) } \\
\text { Henderson-Sellers and Gornitz (1984) } \\
\text { Sud and Smith (1985b) } \\
\text { Cunnington and Rowntree (1986) } \\
\text { Laval (1986) } \\
\text { Laval and Picon (1986) } \\
\text { Wilson et al. (1987a) } \\
\text { Sud and Molod (1988) } \\
\text { Lean and Warrilow (1989) }\end{array}$ & $\begin{array}{l}\text { GISS } \\
\text { NCAR } \\
\text { UKMO } \\
\text { GLAS } \\
\text { GLAS } \\
\text { UKMO } \\
\text { LMD } \\
\text { LMD } \\
\text { NCAR } \\
\text { GLA } \\
\text { UKMO }\end{array}$ & $\begin{array}{l}\text { SM1, SM2 } \\
\text { SM2 } \\
\text { SM1 } \\
\text { SM2 } \\
\text { SM2 } \\
\text { SM2 } \\
\text { SM2 } \\
\text { SM2 } \\
\text { SM2 } \\
\text { SM2 } \\
\text { SM2 } \\
\text { SM2 }\end{array}$ & $\begin{array}{l}\mathrm{R} / \mathrm{G} \\
- \\
\mathrm{R} \\
\mathrm{R} \\
\mathrm{R} \\
\mathrm{R} \\
\mathrm{R} \\
\mathrm{R} \\
\mathrm{R} \\
\mathrm{R} \\
\mathrm{R}\end{array}$ & $\begin{array}{l}42 \mathrm{~d} / 30 \mathrm{~d} \\
3 \mathrm{mon} / 2 \mathrm{mon} \\
>3 \mathrm{mon} / 3 \mathrm{mon} \\
47 \mathrm{~d} / 30 \mathrm{~d} \\
10 \mathrm{y} / 1 \mathrm{mon} \\
6 \mathrm{w} / 1 \mathrm{mon} \\
50 \mathrm{~d} / 30 \mathrm{~d} \\
50 \mathrm{~d} / 30 \mathrm{~d} \\
80 \mathrm{~d} / 30 \mathrm{~d} \\
30 \mathrm{~d} / 10 \mathrm{~d} \\
6 \mathrm{w} / 1 \mathrm{mon} \\
3 \mathrm{y} / 8 \text { mon }\end{array}$ \\
\hline \multicolumn{5}{|l|}{ 2. Soil moisture } \\
\hline $\begin{array}{l}\text { General } \\
\text { Manabe (1975) } \\
\text { Kurbatkin et al. (1979) } \\
\text { Carson and Sangster (1981) } \\
\text { Miyakoda and Strickler (1981) } \\
\text { Shukla and Mintz (1982) } \\
\text { Suarez and Arakawa-discussed in } \\
\quad \text { Mintz (1984) }\end{array}$ & $\begin{array}{l}\text { GFDL } \\
\text { GFDL } \\
\text { UKMO } \\
\text { GFDL } \\
\text { GLAS } \\
\text { UCLA }\end{array}$ & $\begin{array}{l}\text { SM1, SM2 } \\
\text { SM1, SM2 } \\
\text { SM1 } \\
\text { SM1 } \\
\text { SM1 } \\
\text { SM1 }\end{array}$ & $\begin{array}{r}\bar{G} \\
\mathrm{G} \\
\mathrm{R} / \mathrm{G} \\
\mathrm{G} \\
\mathrm{G}\end{array}$ & $\begin{array}{l}-/ 3 \mathrm{mon} \\
-/ 2 \mathrm{mon} \\
>3 \mathrm{mon} / 3 \mathrm{mon} \\
14 \mathrm{~d} / 12 \mathrm{~d} \\
60 \mathrm{~d} / 30 \mathrm{~d} \\
6 \mathrm{w} / 4 \mathrm{w}\end{array}$ \\
\hline $\begin{array}{l}\text { Warrilow (1986) } \\
\text { Laval (1988) } \\
\text { Meehl and Washington (1988) } \\
\text { Blondin (1989) }\end{array}$ & $\begin{array}{l}\text { UKMO } \\
\text { LMD } \\
\text { NCAR } \\
\text { GFDL } \\
\text { ECMWF }\end{array}$ & $\begin{array}{l}\text { SM2 } \\
\text { SM2 } \\
\text { SM2 } \\
\text { SM2 } \\
\text { SM2 }\end{array}$ & $\begin{array}{r}G \\
G \\
R / G \\
R / G \\
G\end{array}$ & $\begin{array}{l}18 \mathrm{mon} / 3 \mathrm{mon} \\
80 \mathrm{~d} / 30 \mathrm{~d} \\
\mathrm{y} / 1 \mathrm{mon} \\
\mathrm{y} / 1 \mathrm{mon} \\
90 \mathrm{~d} / 90 \mathrm{~d}\end{array}$ \\
\hline $\begin{array}{l}\text { Anomalies } \\
\text { Walker and Rowntree (1977) } \\
\text { Rowntree and Bolton (1983) } \\
\text { Yeh et al. (1984) } \\
\text { Cunnington and Rowntree (1986) } \\
\text { Sud and Molod (1988) }\end{array}$ & $\begin{array}{l}\text { UKMO } \\
\text { UKMO } \\
\text { GFDL } \\
\text { UKMO } \\
\text { GLA }\end{array}$ & $\begin{array}{l}\text { SM2 } \\
\text { SM2 } \\
\text { SM2 } \\
\text { SM2 } \\
\text { SM2 }\end{array}$ & $\begin{array}{l}\mathbf{R} \\
\mathbf{R} \\
\mathbf{R}\end{array}$ & $\begin{array}{l}10 \mathrm{~d} / 5 \mathrm{~d} \\
50 \mathrm{~d} / 10 \mathrm{~d} \\
50 \mathrm{~d} / 30 \mathrm{~d} \\
6 \mathrm{w} / 1 \mathrm{mon}\end{array}$ \\
\hline
\end{tabular}


roughness length, and models for soil hydrology and vegetation.

The sensitivity problem in GCMs was discussed by Carson ( $1982 \mathrm{a}$ - at an ECMWF workshop on ABL parameterization ) in the context of UKMO GCM sensitivity tests on sea surface roughness; by Rowntree (1988), with emphasis on albedo and surface moisture; and anonymously in a report of a CAS/WMO Workshop on the ABL over oceans held at ECMWF in 1983.

Most recently, Rowntree (1988), in a review of GCMs and the relation between vegetation and climate, briefly summarized GCM sensitivity studies relating to surface albedo and moisture. Table 2 lists the most relevant studies, where we have made a distinction between the use of soil moisture anomalies and the use of a general moisture formulation or specification (e.g., dry or wet). In the last two columns, the emphasis of the study on regional $(R)$ or global $(G)$ impacts is indicated, together with the model integration time and/ or averaging time of the statistics.

In the case of surface albedo, the major results for regional albedo changes are summarized in Table 3 in terms of gross changes in regional evaporation and precipitation. Two mechanisms can be identified that are consistent with these results-first, that due to Charney (1975), whereby cooling of a local atmospheric column due to increased surface albedo (the result of a loss of vegetation ) produces decreased ascent, a displacement equatorwards of the ITCZ, and reduced precipitation; and second, in regions where precipitation is strongly influenced by evaporation, increased albedo results in reduced net radiation, hence evaporation and precipitation. Thus, in the tropics, Mylne and Rowntree (1991) suggest evaporation from moist

TABLE 3. Sensitivity results of the response of 3D GCM climate simulations to gross changes in surface albedo $\delta \alpha_{s}$. Climate response is shown here in terms of average changes in evaporation $\delta E$, and rainfall $\delta P$ over land. References denoted by an asterisk are discussed in Mintz (1984). These and others are further discussed in Rowntree (1988).

\begin{tabular}{|c|c|c|c|}
\hline Reference & $\delta \alpha_{s}$ & \multicolumn{2}{|c|}{$\left(\mathrm{mm} \mathrm{day}{ }^{-1}\right)$} \\
\hline Charney et al. $(1977)^{*}$ & .21 & -0.8 & -2.0 \\
\hline Chervin $(1979)^{*}$ & .27 & - & -1.7 \\
\hline Carson and Sangster $(1981)^{*}$ & $\begin{array}{l}.20 \\
.10\end{array}$ & -0.95 & $\begin{array}{l}-1.2 \\
-0.4\end{array}$ \\
\hline Sud and Fenessey (1982) & .16 & -0.4 & -0.6 \\
\hline $\begin{array}{l}\text { Henderson-Sellers and Gornitz } \\
\text { (1984) }\end{array}$ & .06 & -0.45 & -0.6 \\
\hline Sud and Smith (1985b) & .06 & - & -1.6 \\
\hline Cunnington and Rowntree (1986) & $\begin{array}{r}.06 \\
-.04\end{array}$ & - & $\begin{array}{l}-0.75 \\
+0.6\end{array}$ \\
\hline Laval and Picon (1986) & increase & decrease & decrease \\
\hline Sud and Molod (1988) & decrease & & increase \\
\hline Lean and Warrilow (1989) & .05 & -0.2 & -0.75 \\
\hline $\begin{array}{l}\text { Planton (1986)-quoted in } \\
\text { Mylne and Rowntree (1991) }\end{array}$ & .10 & -0.1 & -0.2 \\
\hline
\end{tabular}

TABLE 4. Sensitivity studies (other than albedo and surface moisture) involving surface roughness, vegetation, and soils. The abbreviation $\mathrm{mm}$ refers to mean monthly values. Abbreviations as in Table 2 .

\begin{tabular}{|c|c|c|c|}
\hline References & Model & $\begin{array}{l}\text { Regional (R) } \\
\text { or global (G) }\end{array}$ & $\begin{array}{c}\text { Integration } \\
\text { time/ } \\
\text { averages }\end{array}$ \\
\hline \multicolumn{4}{|l|}{ 1. Roughness } \\
\hline Delsol et al. (1971) & GFDL & G & $14 \mathrm{~d}$ \\
\hline Carson (1982a) & UKMO & G & $7 \mathrm{~d}$ \\
\hline Sud and Smith $(1985 a, b)$ & GLAS & $\mathbf{R}$ & $1-2$ mon \\
\hline Heasman (1987) & UKMO & G & $80 \mathrm{~d} / \mathrm{mm}$ \\
\hline Yagai and Tokioka (1987) & MRI & G & $60 \mathrm{~d}$ \\
\hline Sud et al. (1988) & GLAS & G & $1-2$ mon \\
\hline Miller et al. (1989) & ECMWF & G & $90 \mathrm{~d}$ \\
\hline $\begin{array}{l}\text { Smith and Warrilow } \\
\text { (1989) }\end{array}$ & UKMO & $\mathrm{G}$ & $? / 30 \mathrm{~d}$ \\
\hline $\begin{array}{l}\text { Warrilow and Buckley } \\
\text { (1989) }\end{array}$ & UKMO & G & $? / 30 \mathrm{~d}$ \\
\hline \multicolumn{4}{|l|}{ 2. Vegetation and soils } \\
\hline $\begin{array}{l}\text { Henderson-Sellers and } \\
\text { Gornitz (1984) }\end{array}$ & GISS & $\mathrm{G}$ & $\sim 10 \mathrm{y}$ \\
\hline Warrilow et al. (1986) & UKMO & $\mathrm{G}$ & \\
\hline Wilson et al. (1987a) & NCAR & $\mathrm{G}$ & $30 \mathrm{~d} / 10 \mathrm{~d}$ \\
\hline Wilson et al. (1987b) & NCAR & $\begin{array}{l}\text { 1D stand } \\
\text { alone }\end{array}$ & \\
\hline $\begin{array}{l}\text { Dickinson and Henderson- } \\
\text { Sellers (1988) }\end{array}$ & NCAR & $\mathrm{R}$ & $13 \mathrm{mon} / \mathrm{mm}$ \\
\hline Pitman et al. (1989) & $\mathrm{CCM}$ & G & $? / 3$ mon \\
\hline $\begin{array}{l}\text { Warrilow and Buckley } \\
\text { (1989) }\end{array}$ & UKMO & G & $? / 30 \mathrm{~d}$ \\
\hline Lean and Warrilow (1989) & UKMO & - & $3 y$ \\
\hline Sud et al. (1990) & GLA & G & $47 \mathrm{~d}$ \\
\hline Xue and Liou (1990) & 2D & $\mathbf{R}$ & $30 \mathrm{~d}$ \\
\hline Shukla et al. (1990) & NMC & $\mathbf{R}$ & $1 \mathrm{y}$ \\
\hline Nobre et al. (1991) & NMC & $\mathbf{R}$ & $1 \mathrm{y}$ \\
\hline
\end{tabular}

surfaces will be reduced by about $0.6 \mathrm{~mm} \mathrm{day}^{-1}$ for an increase of 0.1 in the surface albedo.

Model results in Table 3 include both noninteractive and interactive soil moisture, and consistently reveal, for an albedo increase

(i) decreased land evaporation;

(ii) decreased land precipitation and, in the globalchange cases, increased precipitation over the sea.

In the two instances of an albedo decrease, the increased precipitation emphasizes the consistency of the overall results. Much of the earlier work was biased towards studies in semiarid regions, using models without canopy representation. Mylne and Rowntree (1991) have summarized model results for regions equatorwards of 20 degrees, and looked specifically (using the UKMO GCM) at the impact of tropical deforestation on albedo changes and their impact on the atmosphere. Their main result suggests a $20 \%$ decrease in regional rainfall for a 0.1 increase in albedo, with more than one-half of this rainfall decrease being the result of changed moisture convergence. This response is consistent with 
several tropical deforestation studies reported in the literature (see section $5 b$ ).

The effect of albedo changes on cloudiness has not been so readily identified; however, in one of the studies where ocean temperatures were not prescribed (Henderson-Sellers and Gornitz 1984), the expected global cooling resulting from an albedo increase was obtained. All of the albedo changes prescribed in the above experiments were large compared to those occurring due to present or expected land-use change. According to Henderson-Sellers and Gornitz (1984), the change in global surface albedo due to land-cover transformations in the 30 -year period up to the early 1980 s was about 0.0005 only.

The effect of albedo changes on atmospheric circulation has been alluded to in Laval and Picon (1986) in their study of the Sahelian climate. Thus, concomitant changes in circulation and precipitation were produced in response to albedo changes. Higher albedo produced lower rainfall in the Sahel, related to stronger low-level easterlies and a decreased tropical easterly jet. The results are consistent with that of Sud and Smith (1985b) whose model study showed that the Indian monsoon was significantly weakened by an increase in albedo (Table 3 ).

For surface-moisture sensitivity studies (see Table 2) using GCMs, the major effects of gross soil moisture changes on the model-simulated climate were as follows:

(i) With prescribed dry continental surfaces (no evaporation ) continental rainfall was small except in the tropics. For example, monthly average evaporation and precipitation for the North American and Eurasian land masses were close to zero. In the tropics (July conditions were usually considered), moisture convergence from the oceans was dominant.

(ii) For prescribed saturated continental surfaces with potential evaporation $(x=1)$, most of the midlatitude continental areas were wet, with the extensive North American and Eurasian land areas having monthly mean evaporation and precipitation increase (from the $x=0$ case) to about $4 \mathrm{~mm} \mathrm{day}^{-1}$. The peripheries of the tropical wet regions were the most sensitive to soil moisture, while rainfall remained low in the desert regions in the subtropics. Overall, the experiments with regional anomalies do not give significant and consistent results. In contrast, global changes in soil moisture status tend to produce decreased precipitation over land when the soil is dry, except in tropical regions where increased moisture convergence maintains precipitation amounts.

The foregoing results for surface albedo and soil moisture impacts are broadly consistent with simple conceptual ideas. Thus, Eqs. (12) and (14) combined show that increases in $\alpha_{s}$ tend to decrease the available energy $(H+\lambda E)$, and hence most probably the evap- oration. For a purely $1 \mathrm{D}$ situation, drying the soil will reduce evaporation to zero, and hence reduce precipitation. Where horizontal moisture convergence is important, the effects of soil moisture changes locally are not readily deduced.

In the last ten years or so, most GCM studies of relevance to this review have involved the impact of land-surface changes and have used only a few model variables or fields to assess the response: precipitation, cloudiness, and evaporation, predominantly. Studies of interest, other than for albedo or soil moisture, are summarized in Tables 4 and 5. Since Mintz (1984) and Rowntree (1988) have dealt with the albedo and surface moisture sensitivity, we wish to concentrate in the remainder of this section on the results of the GCM sensitivity to surface roughness and vegetation representation.

\section{b. Surface roughness}

Conceptually, we turn to the combination equation [Eq. (12)] to provide guidance on the possible impact of roughness changes upon evaporation. An increase in $z_{0}$ decreases $r_{a}$, and hence increases the aerodynamic contribution to the potential evaporation, and probably

TABLE 5. Sensitivity studies (other than albedo and surface moisture) involving the diurnal cycle and the ABL. SGV refers to subgrid variability. Abbreviations as in Tables 2 and 4.

\begin{tabular}{|c|c|c|c|}
\hline References & Model & $\begin{array}{l}\text { Regional }(R) \\
\text { or global }(G)\end{array}$ & $\begin{array}{l}\text { Integration } \\
\text { time/ } \\
\text { averages }^{a}\end{array}$ \\
\hline \multicolumn{4}{|l|}{ 1. Diurnal cycle } \\
\hline $\begin{array}{l}\text { Delsol et al. (1971) } \\
\text { Hansen et al. (1983) } \\
\text { Randall et al. (1985) } \\
\text { Wilson and Mitchell } \\
\quad(1986)\end{array}$ & $\begin{array}{l}\text { GFDL } \\
\text { GISS } \\
\text { UCLA } \\
\text { UKMO }\end{array}$ & $\begin{array}{l}G \\
G \\
G \\
G\end{array}$ & $\begin{array}{c}14 \mathrm{~d} \\
>3 \mathrm{mo} \\
3 \mathrm{yr} / \mathrm{mm} \\
\sim 1 \mathrm{mo}\end{array}$ \\
\hline \multicolumn{4}{|l|}{ 2. Averaging (SGV) } \\
\hline $\begin{array}{l}\text { Sud and Smith } \\
\quad(1984)\end{array}$ & GLAS & $\mathrm{G}$ & $1-2 \mathrm{mo}$ \\
\hline \multicolumn{4}{|l|}{ 3. ABL clouds } \\
\hline $\begin{array}{l}\text { Randall et al. (1985) } \\
\text { Slingo et al. (1989) }\end{array}$ & $\begin{array}{l}\text { UCLA } \\
\text { UKMO }\end{array}$ & $\begin{array}{l}G \\
G\end{array}$ & $\begin{array}{c}3 \mathrm{yr} / \mathrm{mm} \\
2 \mathrm{yr}\end{array}$ \\
\hline \multicolumn{4}{|l|}{ 4. ABL mixing } \\
\hline $\begin{array}{l}\text { Delson et al. (1971) } \\
\text { Hansen et al. (1983) } \\
\text { Miyakoda and Sirutis } \\
\quad \text { (1977) }\end{array}$ & $\begin{array}{l}\text { GFDL } \\
\text { GISS }\end{array}$ & $\begin{array}{l}\mathrm{G} \\
\mathrm{G}\end{array}$ & $\begin{array}{c}14 \mathrm{~d} \\
3 \mathrm{mo} \text { to } 5 \mathrm{yr}\end{array}$ \\
\hline \multicolumn{4}{|l|}{ 5. ABL depth } \\
\hline Randall et al. (1985) & UCLA & G & $3 \mathrm{yr} / \mathrm{mm}$ \\
\hline
\end{tabular}

${ }^{a} \mathrm{~mm}$ refers to mean monthly. mo $\equiv$ month. 
TABLE 6. Impact of canopy on regional climate (Amazonia); $\mathrm{C}$ control GCM simulation (forest or high roughness); Exp-experimental GCM simulation (deforested or low roughness). All canopy results are for annual averages (or longer). $E$ is evaporation, $P$ is precipitation, and $R$ is surface runoff (all in $\mathrm{mm} \mathrm{day}^{-1}$ ).

\begin{tabular}{|c|c|c|c|c|c|c|}
\hline \multirow{2}{*}{$\frac{\text { Reference }}{\text { Dickinson and }}$} & \multicolumn{2}{|l|}{ Model } & \multicolumn{2}{|c|}{$\begin{array}{l}E \quad P \\
\text { mm day }\end{array}$} & ${ }_{-1}^{R}$ & $\begin{array}{l}T_{a} \\
\left({ }^{\circ} \mathrm{C}\right)\end{array}$ \\
\hline & NCAR/BATS & $\mathrm{C}$ & 5.9 & 9 & 4 & 25 \\
\hline $\begin{array}{l}\text { Henderson- } \\
\text { Sellers (1988) }\end{array}$ & & $\operatorname{Exp}$ & 5.2 & 9 & 4 & 26.5 \\
\hline Lean and Warrilow & UKMO & $\mathrm{C}$ & 3.1 & 6.6 & 3.4 & 23.6 \\
\hline$(1989)$ & & Exp & 2.3 & 5.3 & 3 & 26.0 \\
\hline Shukla et al. (1990) & NMC/SiB & $\mathrm{C}$ & 4.5 & 6.7 & - & 23.5 \\
\hline & & Exp & 3.2 & 5.0 & - & 26.0 \\
\hline Nobre et al. (1991) & as above in Sh & kla et & al. $(1$ & 90) & & \\
\hline
\end{tabular}

tends to increase both evaporation and precipitation. The reader should note that high-roughness land surfaces tend to have (i) a relatively low albedo (Fig. 1), and hence the capacity to accomodate higher values of net radiation; (ii) low soil heat fluxes; (iii) low aerodynamic resistances. All three factors, according to Eq. (12), tend to produce increases in the potential evaporation. So far as regional or global effects of surface changes are concerned, the preceding arguments suggest that increased evaporation and precipitation result from decreased albedo, increased soil moisture, and increased roughness.

Model studies covering a range of time scales and involving several GCMs suggest an impact of roughness on circulation and precipitation, particularly for the longer time scales, and with large changes in roughness. In many cases, changes were insufficient for one to expect a significant response (e.g., Miller et al. 1989). To see this, consider the geostrophic drag coefficient $\left(C_{G}\right)$, upon which regional and global surface fluxes depend, and its dependence on roughness length. The variation is illustrated in Fig. 6 according to a wellknown boundary-layer similarity relation. The depth scale $h$ can be taken as the neutral boundary-layer depth, and set at a value of $1 \mathrm{~km}$ for present purposes. The curve shows that significant changes in $C_{G}$ (of order $25 \%-50 \%$ ) require changes in $z_{0}$ of one to two orders of magnitude, and that changes in $z_{0}$ of only a factor of two or so produce insignificant changes in $C_{G}$.

Major GCM studies on time scales less than about 10 days are those due to Delsol et al. (1971) and Carson (1982a, in ECMWF workshop report), and on longer time scales those due to Sud and Smith $(1985 \mathrm{a}, \mathrm{b})$ and Sud et al. (1988), both using the GLAS model, and Heasman (1987) using the UKMO model. We concentrate below on the longer time scale studies.

In the study of Sud and Smith (1985a), the influence of the low surface roughness of deserts was examined for the July circulation around the globe, with focus in the Sahara region. A decrease in $z_{0}$ over all major deserts (from $0.45 \mathrm{~m}$ to $0.0002 \mathrm{~m}$ ) produced, around the Sahara, a significant reduction in regional precipitation, related to changes in regional circulations, a shift of the ITCZ southwards, and a reduction in the cross-isobaric moisture convergence into the Sahara region. In other deserts, which had little rainfall in their July control simulation, there was little significant change. Sud and Smith (1985b) concentrated on the impact of a range of surface changes upon the July circulation over India. One of their experiments involved roughness changes identical to those studied in Sud and Smith (1985a). Again, the roughness decrease (from $0.45 \mathrm{~m}$ to $0.0002 \mathrm{~m}$ ) produced a significant decrease in precipitation (of about $1 \mathrm{~mm} \mathrm{day}^{-1}$ ).

The study of Sud et al. (1988) probably provides the biggest global change in $z_{0}$ over all land surfaces (from $0.45 \mathrm{~m}$ to $0.0002 \mathrm{~m}$ ) with which to assess the atmospheric response. Their results are based on the average of three control and experiment runs, each run representing an integration through the month of July. The reduced roughness produced about a two-fold increase in the boundary-layer wind speed and, at the same time, a two-fold decrease in the surface stress. There was almost no change in the surface evaporation and surface heat flux. There was, however, a large change in the horizontal convergence of the water vapor transport in the boundary layer and a corresponding large change in the land-sea precipitation distribution (see Fig. 7a). Statistical considerations showed that some of these changes, for example, in the sub-Sahara and Amazon Basin regions were significant (see Fig. 7b). For example, the mean July evaporation for the Amazon changed very little with the roughness decrease, though the precipitation decreased from about $4 \mathrm{~mm}$ day $^{-1}$ to about $2 \mathrm{~mm}$ day $^{-1}$. This result is consistent with that found by Lean and Warrilow (1989) using the UKMO model.

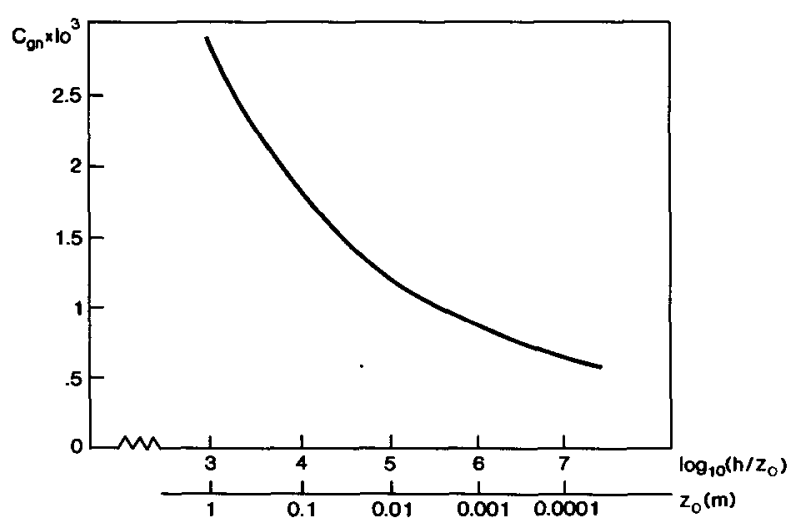

FIG. 6. Variation of the neutral geostrophic drag coefficient with roughness length based on

$$
C_{G}=k^{2} /\left\{\left[\ln \left(h / z_{0}\right)-A\right]^{2}+B^{2}\right\},
$$

where $A=1, B=4.5$, and $h=1 \mathrm{~km} ; k$ is the Karman constant taken as 0.4 ( see Garratt 1992, chapter 3 ). 

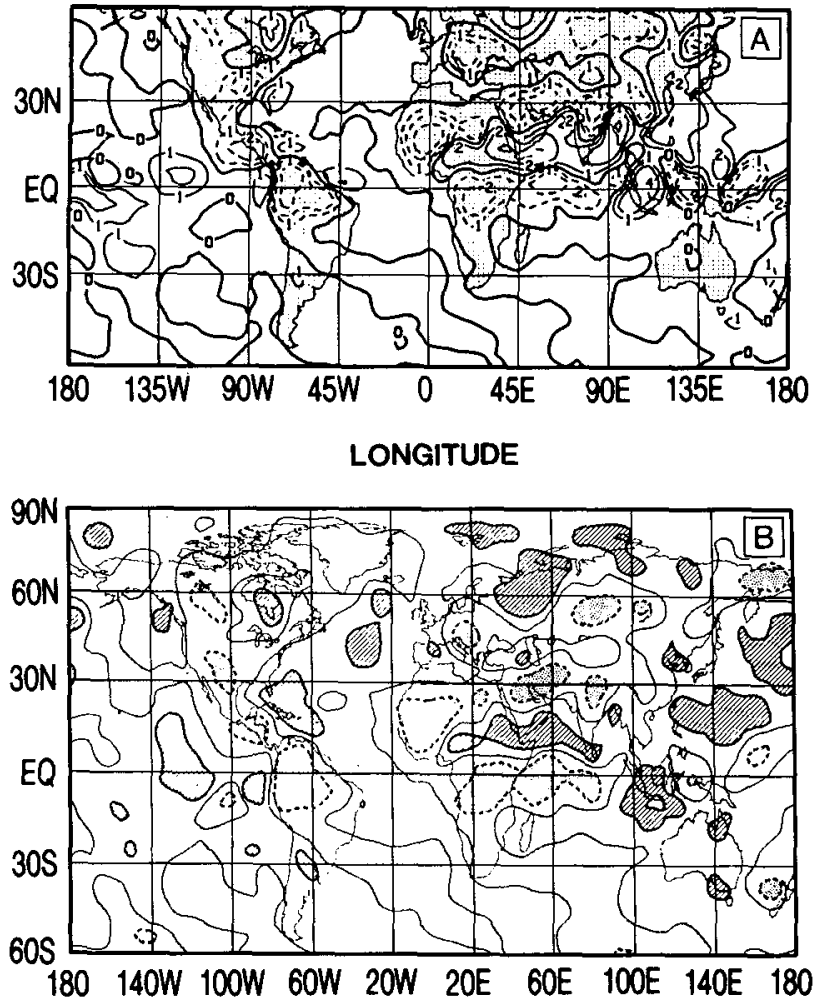

FIG. 7. (a) Difference in the total July precipitation between the experimental and control simulations averaged for three model simulations each. Contours are for $\pm 0,1,2,4,8,12,16, \ldots \mathrm{mm} \mathrm{day}^{-1}$; dashed lines show negative values. (b) Student's t-test analysis of the rainfall differences between the control and experiment runs; $t$ greater than \pm 2.8 represents over $95 \%$ significance. The dotted and ruled shaded areas show the regions of $95 \%$ confidence for dry and wet conditions. From Sud et al. (1988).

In the works of Sud and Smith $(1985 \mathrm{a}, \mathrm{b})$ and Sud et al. (1988) several experimental runs were made in order to evaluate the statistical significance of the results relative to the natural variations occurring in the model climate (related to interannual variability). This statistical evaluation is an important component of any sensitivity/impact study-in their case, differences (experimental minus control) in various physical fields were found to be statistically significant, since they were often two to three times larger than the sample standard deviations. The study of Sud et al. (1988) used a model with a prescribed soil wetness and with no treatment of vegetation or interactive soil moisture. Their study nevertheless suggests that the height of the earth's vegetation cover, which is the main determinant of the land-surface roughness (orography is also important), has a large influence on the boundary-layer water-vapor transport convergence and the rainfall distribution.

The results just mentioned serve to emphasize the relative effects of increases in surface albedo and decreases in surface roughness. For example, of the studies relating to the Sahara region (Chervin 1979; Sud and Smith 1985a), the influence of a decrease in roughness is qualitatively the same as that of an increase in surface albedo. For the Amazon region, the comparable effects of albedo and roughness changes were estimated by Lean and Warrilow (1989) using the UKMO GCM. Annual changes in precipitation and evaporation were as follows:

$\begin{array}{lcc} & \delta E & \delta P \\ \text { Albedo change: } & \left(\mathrm{mm} \mathrm{day}^{-1}\right) & \left(\mathrm{mm} \mathrm{day}^{-1}\right) \\ \quad 0.14 \text { to } 0.19 & -0.20 & -0.75 \\ \text { Roughness change: } & & \\ 0.79 \text { to } 0.04 m & -0.43 & -0.69 .\end{array}$

\section{c. Vegetation}

The gross effects of incorporating a canopy scheme into a GCM are as follows: a decrease in albedo in going from bare soil to vegetation (Fig. 1); an increase in $z_{0}$ over that for bare soil (Fig. 2); access to deeper soil moisture and resultant physiological control of evapotranspiration through a bulk stomatal resistance; and the interception and reevaporation of water from foliage. Henderson-Sellers and Gornitz (1984) made the point that to not incorporate a canopy submodel in a GCM, but simply to have albedo and roughness changes, may not properly represent surface-change effects. Five major studies are known where the sensitivity of global and regional climate to vegetation has been studied through introduction of canopy submodels (Dickinson and Henderson-Sellers 1988; Lean and Warrilow 1989; Sud et al. 1990; Shukla et al. 1990; Nobre et al. 1991). In four of these (all but the study of Sud et al.), the focus was on the climatic impact of tropical deforestation.

Dickinson and Henderson-Sellers (1988), using the BATS canopy model (Dickinson et al. 1986; Wilson et al. 1987b), together with full 3D simulations in the NCAR CCM, studied regional climate response to removal of the Amazonian forest (analogous to the earlier study of Henderson-Sellers and Gornitz 1984). A control run was compared with observations, in terms of mean monthly precipitation and mean sea level (MSL) pressure over South America, and then with the test run with deforestation. In addition, comparisons were made with 1D stand-alone simulations to demonstrate similar behavior in terms of the local/regional response. Broadly, the change from forest to grass on such a large scale produced, after several months, significant increases in near-surface temperatures (up to 3-5 K) and decreases in evapotranspiration. In addition, the annual mean precipitation decreased by 0.25 $\mathrm{mm} \mathrm{day}^{-1}$, though the statistical significance of this change (and that of MSL pressure pattern changes) was marginal.

Subsequently, Lean and Warrilow (1989), Shukla et al. (1990), and Nobre et al. (1991) have all investigated the impact of Amazonian deforestation on regional climate. In Lean and Warrilow (1989), the 
UKMO model was combined with a simple soil-canopy scheme (see Warrilow et al. 1986). The scheme included four soil levels, interception of rainfall by the canopy, and the geographical variations of land-surface parameters and soil types. They ran 3-year control (forest) and deforestation (tropical pasture) experiments. In the studies of Shukla et al. (1990) and Nobre et al. (1991), the US NMC model was combined with $\mathrm{SiB}$ (see also Sato et al. 1989a, 1989b), and 1-year control (forest) and deforestation (degraded tropical pasture-mainly grass) experiments were performed. The later study was basically an extension of the earlier one, but with greater emphasis on the simulations at the diurnal and monthly time scale, and comparison with observations. The main results can best be assessed by reference to the changes in precipitation, evaporation, and near-surface air temperature produced by the change in surface type (see Fig. 8). These changes are summarized in Table 6 together with comparable results from Dickinson and Henderson-Sellers (1988).
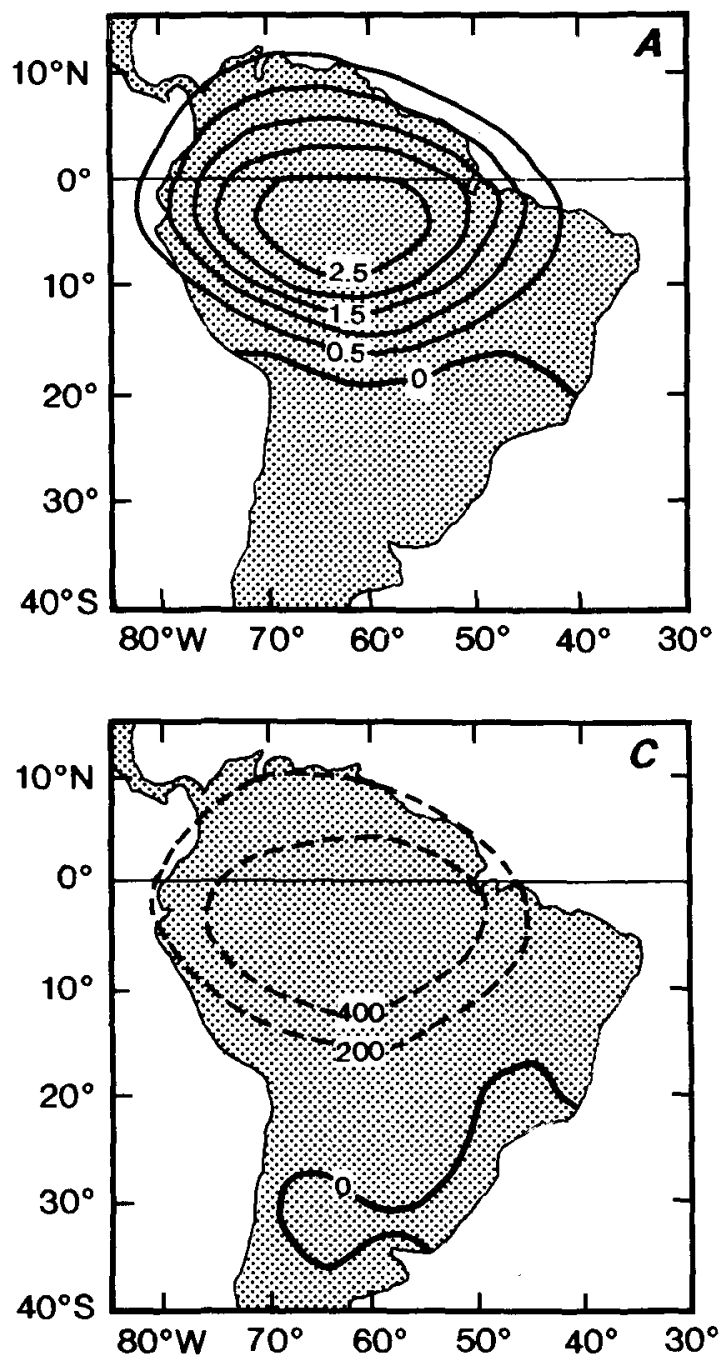

The results from Lean and Warrilow (1989) and the two NMC model studies are remarkably consistent, in showing reductions in long-term evaporation and precipitation, and increases in near-surface temperature. Nobre et al. identified a larger regional decrease in precipitation over evaporation, implying a decrease in the dynamical convergence of moisture flux. Additional simulations by Lean and Warrilow (for 8-month periods) discussed in their paper reveal that the increase in temperature is associated with the roughness decrease, with albedo playing a relatively minor role. But the two land parameters seem to play a comparable role in the variations of the hydrological budget. The forest canopy is wet for much of the year, so a decrease in evaporation is to be expected as roughness decreases [Eq. (12)]. One interesting conclusion of both the NMC model studies relates to the implied longer dry season induced by deforestation. This has serious ecological implications, since tropical forests are both sustained by the absence of a prolonged dry season and

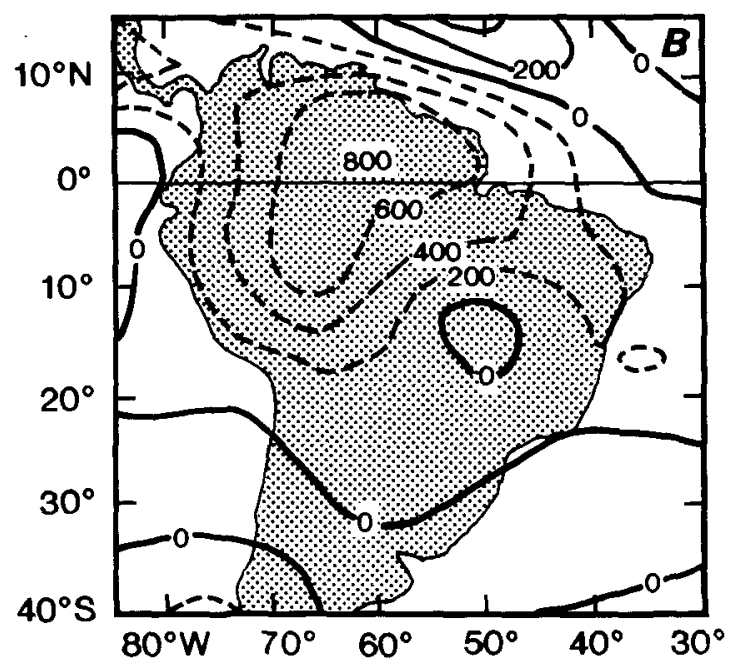

Fig. 8. Model differences between 12-month means (calendar year) of deforestation and control cases (deforested minus control) for South America, showing: (a) surface temperature increase in ${ }^{\circ} \mathrm{C}$; (b) total precipitation changes in $\mathrm{mm}$ (dashed lines indicate a decrease); (c) evapotranspiration decrease in mm. From Shukla et al. (1990). 
would be more difficult to reestablish under such conditions.

All of the preceding tropical deforestation experiments involve, with the transformation from forest to degraded pasture, relatively large roughness decreases and albedo increases, giving impacts consistent with earlier individual roughness and albedo sensitivity studies. In contrast, the study of Sud et al. (1990) evaluated the impact of introducing a complex soil-canopy scheme [the Simple Biosphere Model (SiB)] into the GLA GCM by comparing model simulations with and without $\mathrm{SiB}$, mainly in terms of mean January and July statistics. Ensemble sets of four January and July simulations were made, each set containing two runs: one with and one without $\mathrm{SiB}$. In the control runs, soil moisture was prescribed (though it was time varying) and so was noninteractive, while in contrast the $\mathrm{SiB}$ scheme involves interactive soil moisture.

The main results of the comparisons showed that $\mathrm{SiB}$ simulates much lower evapotranspiration rates over land for both vegetated and bare soil regions, with generally greater sensible heat fluxes (though not exclusively so) and lower levels of net radiation. The changes in the surface fluxes were accompanied by large and statistically significant changes in the simulated rainfall, particularly in the tropics and the summer hemisphere. Globally, the SiB-GCM evaporation over land decreased by nearly $40 \%$ of that evaluated in the Control GCM, with precipitation decreasing by only $30 \%$, and surface net radiation decreasing by some $15 \%-20 \%$. The impact of $\mathrm{SiB}$ on the global hydrological cycle in the GCM is shown in Fig. 9 in terms of surface net radiation, sensible heat flux, evaporation, and precipitation. The SiB GCM produced reduced evaporation over all land regardless of the vegetation cover. In vegetated regions, the stomatal function of leaves reduces daytime evapotranspiration from the evaporation calculated with a bucket scheme, while in bare-soil areas the use of a soil moisture scheme (in SiB) with a thin near-surface layer ensures rapid drying of the soil near the surface and consequent reduction in evaporation. The reduction in the surface net radiation for all continental regions seems to have been due to both the reduction in evaporation, leading to increased surface temperatures and outgoing longwave fluxes, and to generally increased surface albedos associated with the $\mathrm{SiB}$ scheme.

\section{Main sensitivity results- $\mathbf{A B L}$ \\ a. ABL turbulence and depth of mixing}

Few GCM sensitivity studies have been carried out on the impact of $\mathrm{ABL}$ parameterization schemes. This is basically because of the difficulty in evaluating the sensitivity of climate to ABL processes, as compared with surface representation. Nevertheless, there are a few relevant studies ( see Table 5) that include the roles of the diurnal cycle and the ABL depth and mixing.
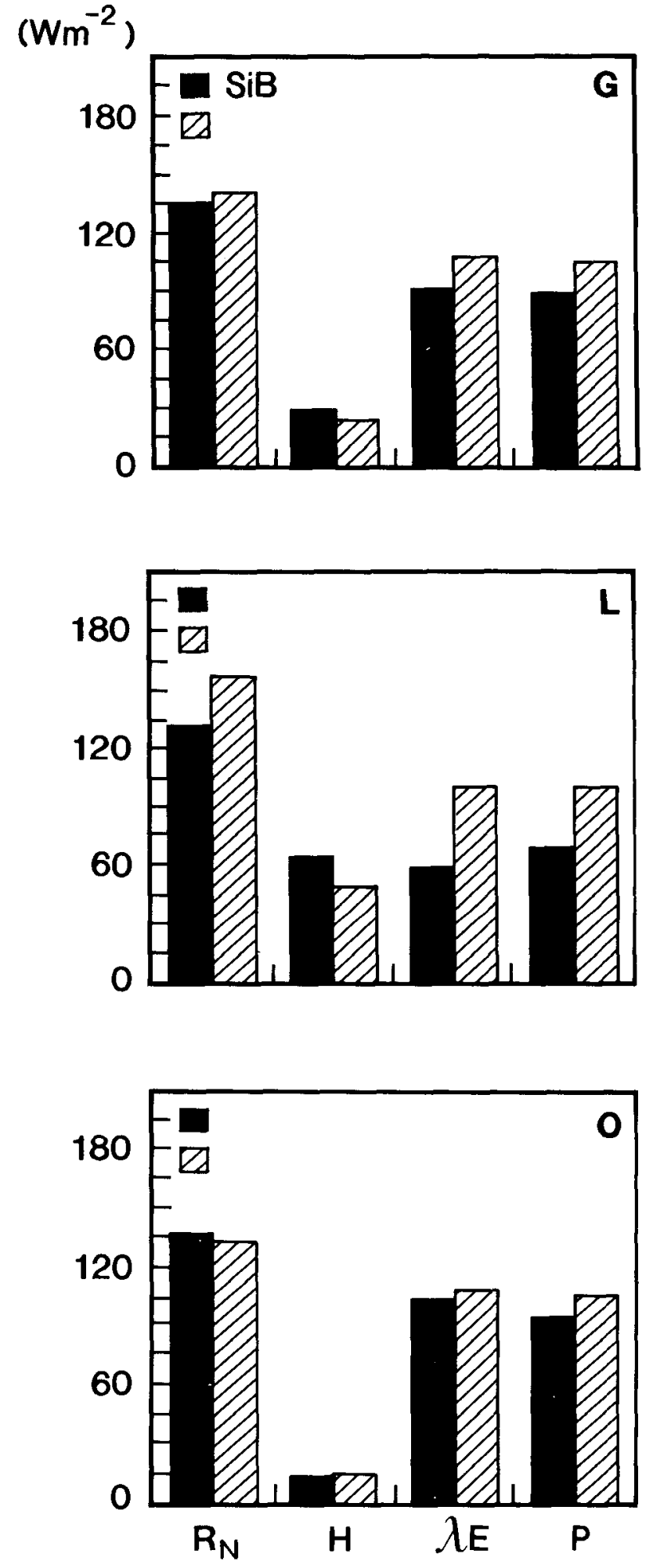

FIG. 9. Model simulated July surface energy budget components in $\mathrm{W} \mathrm{m}^{-2}$ for the three regions: entire Earth $(\mathrm{G})$, land $(\mathrm{L})$, and oceans (O) from GCM simulations with (solid bar) and without (hatched bar) the $\mathrm{SiB}$ scheme. The components are: net radiation, sensible heat flux, and latent heat flux. Precipitation is also shown. From Sud et al. (1990). 


\section{1) Diurnal CYCLE}

The ABL structure, land surface temperature, and surface fluxes are strongly dependent on the diurnal cycle of solar insolation, though the diurnal cycle is not included in all GCMs. If accurate surface fluxes, for example, are required in climate simulations (noting that there is a highly nonlinear dependence of fluxes on stability) or if the effects of clouds are to be properly included (and their effects on climate to be modeled correctly) a diurnal cycle is necessary. Randall et al. (1985), using the UCLA GCM, found that the model's simulated July climate is much more realistic with the diurnal cycle than without it.

\section{2) THE ABL DEPTH AND MIXING}

In several studies (Delsol et al. 1971; Miyakoda and Sirutis 1977; Louis et al. 1982; Hansen et al. 1983; Hart et al. 1988), the impacts of several parameterization changes, including ABL schemes, were discussed only briefly. In many, improvements in the simulated climate were noted but none can be classed as systematic studies. In Randall et al. (1985), simulations were described with variable and fixed ABL depths. Their results confirmed the idea that variability in the $A B L$ depth influences the general circulation primarily by regulating the intensity of the cumulus convection over land.

Slingo et al. (1988) used an improved version of the UKMO 11-level model, and predicted the ABL depth so as to facilitate stratocumulus formation. Improved cloud fields and radiation budgets were claimed. In a more detailed follow-up paper Slingo et al. (1989) discussed the effects of improved physics on simulations of cloudiness and the earth's radiation budget in particular. Main changes involved cumulus convection parameterization, ABL mixing, and the surface heat flux. These modifications were made so as to improve the earlier model's poor simulation of low cloud over subtropical oceans. Revised simulations agreed better with satellite observations.

\section{b. ABL clouds}

The presence of clouds plays a crucial role in the radiation balance of the atmosphere and earth's surface, and hence in the general circulation and climate. $\mathrm{ABL}$ clouds are treated very crudely in most models, with little dependence on $A B L$ mixing, entrainment across the ABL or cloud-layer top, or on ABL depth. All of these factors appear to be crucial to the presence or otherwise of low-level layer clouds. Consequently, in most GCMs there is an excess of stratocumulus and stratus globally, particularly in high latitudes and in the central subtropical oceans, and a deficit of stratocumulus in the subtropical oceans west of the continents where maxima are observed. Unfortunately, too few model studies have been involved in evaluating the sensitivity of low cloudiness to ABL schemes and other effects, and improvements have been found for quite different reasons (this seems to depend on the model used).

We use two examples to illustrate the problem (see also Hansen et al. 1983). In the first example, Slingo et al. (1989) described how cloudiness in the UKMO model was improved (i.e., decreased globally) by removing a dependence upon a low-level $\theta$ gradient (causing cloud tuning problems). In the subtropical ocean areas with deficient stratocumulus, the $A B L$ scheme was found to be producing too deep and dry an ABL. Improvement was produced when the ABL top was allowed to coincide with the lowest inversion (and was thus generally much shallower in these oceanic regions of interest), and with modified, stability-dependent diffusivities. The excess stratus at high latitudes was assumed to be the result of negligible entrainment across the cloud top.

Such a problem had been dealt with earlier in the UCLA model, and its impact illustrated well in the study of Randall et al. (1985). They used the UCLA model for seasonal simulations of climate and to evaluate the sensitivity to three aspects of $\mathrm{ABL}$ and cloud parameterization: layer-cloud instability ( $\mathrm{LCI}$ ) related to stratocumulus dissipation, entrainment, and interaction with $\mathrm{ABL}$ turbulence; $\mathrm{ABL}$ depth; and diurnal cycle. Removing the LCI, which basically cuts off entrainment of dry air into the cloud from above, produced increased and unrealistic cloudiness. Fixing the ABL depth produces a pronounced and unrealistic increase in cumulus precipitation over land.

\section{Comments on the deforestation experiments}

The impact of albedo, roughness, and the surface type upon the near-surface climate and rainfall has been clearly demonstrated in a number of GCMs. Inclusion of vegetation in the surface scheme of a GCM ensures a more realistic representation of surface roughness, surface albedo, and surface hydrology, and hence the partitioning of available energy into sensible and latent heat fluxes. This improvement in the parameterization of surface processes does not ensure better climate simulations, however, particularly if the representation of other physical processes in the GCM (e.g., ABL mixing and evolution; clouds; precipitation; radiation) is manifestly inferior to that for the surface. Hence, in the long term, improvements in all aspects of a GCM are required, which requires some degree of forward planning, coordination, endeavor, and adequate resources.

The four model studies on tropical deforestation, and the study of Sud et al. (1990) provide a valuable guide to the performance of contemporary GCMs, most of these studies involving experimental model versions with detailed canopy schemes. The studies in particular provide information on the simulated cli- 

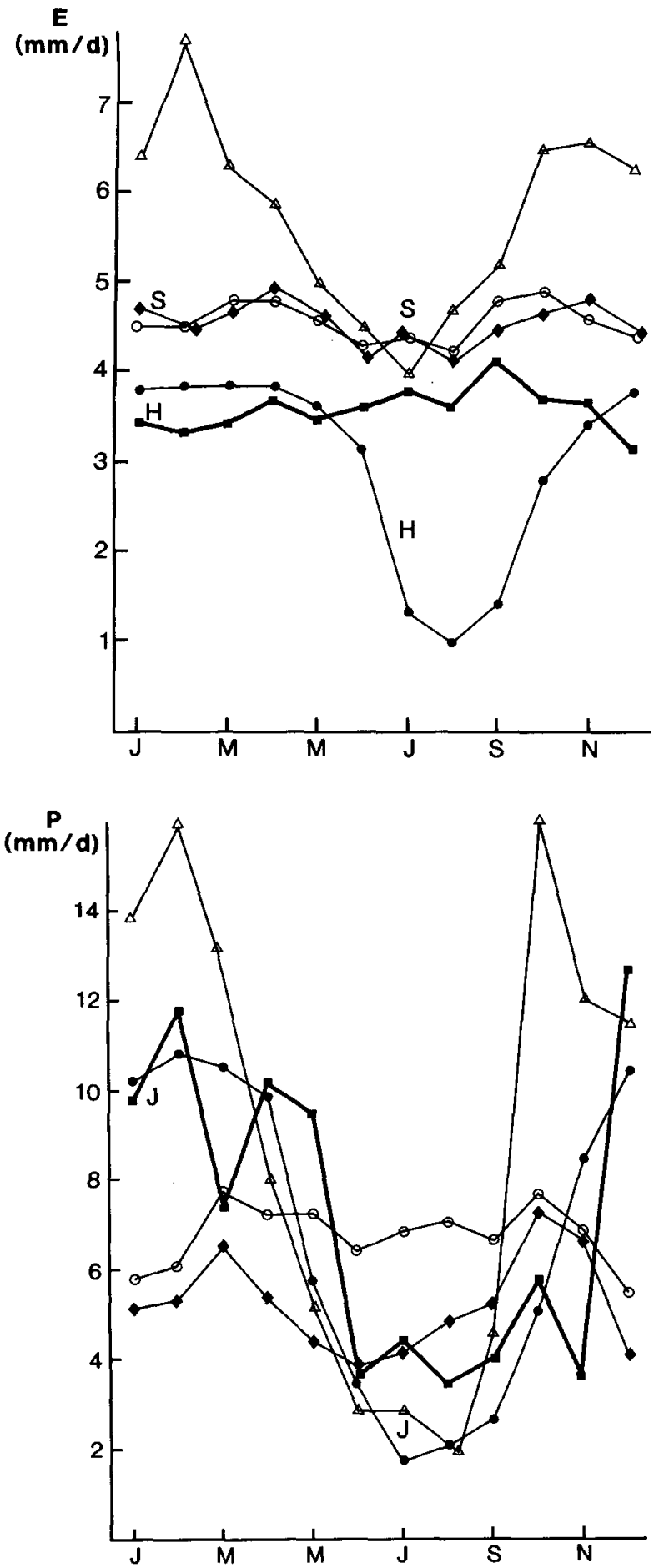

FIG. 10. Annual cycle (mean monthly values) of (a) evaporation and (b) precipitation for Amazonia, based on model simulations and observations. The observations of Shuttleworth (1988) are shown (heavy line, ) together with summer and winter values from Henning (1989) for evaporation ( $\mathrm{H}$ ) and Jaeger (1976) for precipitation (J). Model simulations as follows: UKMO model $(\bullet)$ from Lean and Warrilow (1989); NMC model $(O, \$)$ from Shukla et al. (1990) and Nobre et al. (1991), respectively; NCAR model $(\triangle)$ from Dickinson and Henderson-Sellers (1988); GLA model (S) from Sud et al. (1990). mate of an extensive continental region (Amazonia in this case) that can be used to assess the ability of models to simulate the annual cycles of evaporation, precipitation, and radiation, and to identify model weaknesses through model intercomparison and comparison with observations, in relation to the vegetation parameterizations, or to simplifications elsewhere in the model.

\section{a. Simulation of annual cycles at the surface}

We show in Fig. 10 the annual cycles of monthly precipitation and evaporation for the Amazonian region as simulated in the GCMs used in the deforestation experiments. They are compared with the observations at Manaus over a two-year period reported in Shuttleworth (1988) and, for evaporation, with values deduced from the maps of Henning (1989) for January and July (these imply a seasonal variation that is totally absent in the Shuttleworth observations). The additional precipitation values are taken from Jaeger (1976). Differences between the models are obvious and significant, and not all simulate the marked variation in rainfall between the dry and wet seasons. In the case of evaporation, most models give overestimates, with two demonstrating a pronounced seasonal variation, and the other three showing little variation from month to month.

With the evaporation results in mind, it is instructive to consider the simulation of surface net radiation for Amazonia. Indeed, Dickinson (1989) has suggested that the poor simulation of net radiation was the primary cause of the significant differences between observations and the NCAR model simulations of evaporation and other quantities. Values of the component radiative fluxes or the net radiation are not given in any great detail in any of the published deforestation works, though the net radiation for January and July for several regions is given in Sud et al. (1990). Monthly values of net radiation associated with the NCAR simulations have been presented and discussed by Shuttleworth and Dickinson (1989), however. For the purposes of the present study, the author has drawn upon archived model data (which include surface net radiation) obtained from several GCM groups for a study of the regional surface energy balance. We show in Fig. 11 the annual cycle for Amazonia, together with the observations of Shuttleworth (1988) and the indirect climatological data of Henning (1989) for January and July. The comparison reveals the tendency for the models shown here to overestimate the net radiation, even allowing for improvements produced by introducing new canopy schemes ( $\mathrm{SiB}$ for several of the GCMs) and updated surface albedos. The impact of SiB upon the simulated climate, and upon the surface net radiation in particular, is clear in the study of Sud et al. (1990). Their Table 2 reveals reduced levels of net radiation for all continental regions, for both January and July, when SiB is introduced. Yet as the two 


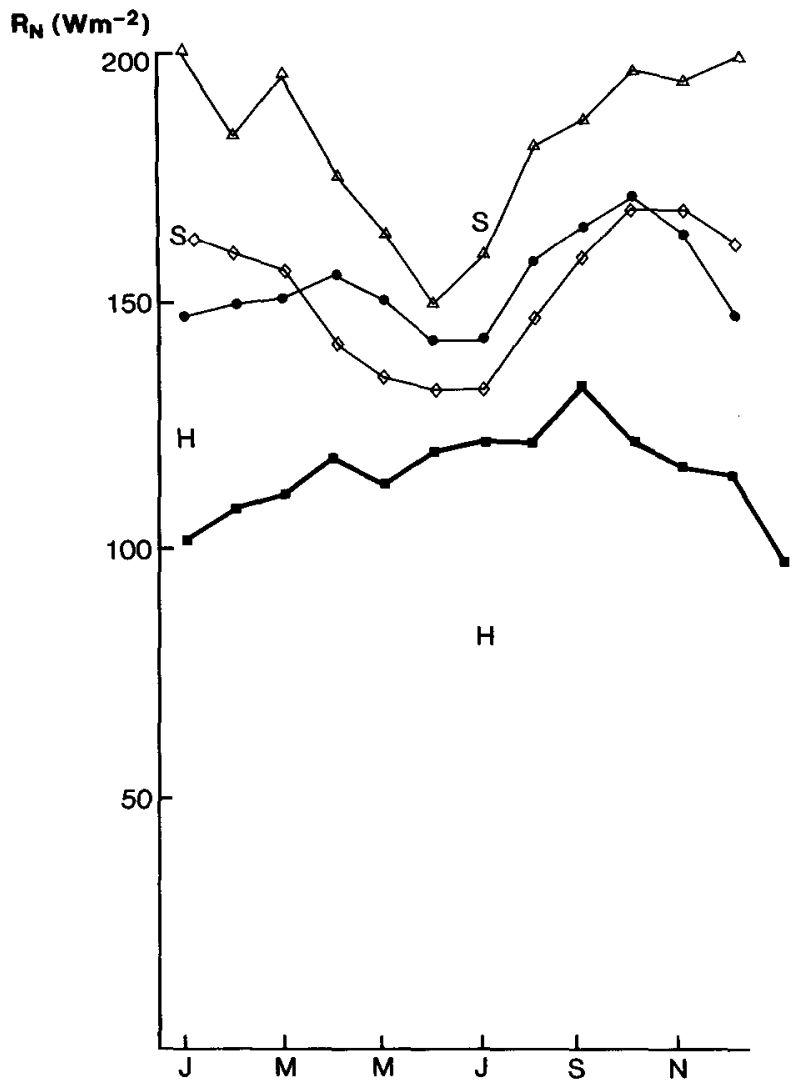

FIG. 11. Annual cycle (mean monthly values) of surface net radiation for Amazonia, based on model simulations and observations. The observations published in Shuttleworth and Dickinson (1989) are shown (heavy line, $\boldsymbol{\nabla}$ ), together with inferred values $(\mathbf{H})$ for summer and winter from Henning (1989). Model values are: NCAR model $(\triangle)$ from Shuttleworth and Dickinson (1989) and GLA model (S) from Sud et al. (1990), together with those based on GCM data archives (for models with canopy schemes and modern albedo values) as follows: UKMO model (๑); NMC model with $\mathrm{SiB}(\diamond)$.

plotted values in Fig. 11 show, these are still much too high. Given that the net radiation is too high, it is then likely that evaporation will be so, since it tends to be close to potential rates for most of the year (Shuttleworth 1988) and thus strongly controlled by the level of net radiation (Priestley and Taylor 1972).

\section{b. Differences in the simulated annual cycles}

The correct simulation of the annual cycle of net radiation is an important factor so far as regional climate, and its response to surface changes, are concerned. In the simulation of evaporation (Fig. 10), differences in the annual cycles simulated by the models are likely due to a number of factors. Differences in the simulated net radiation (Fig. 11) are probably a major factor, and these differences will almost certainly be due to differences in cloud-cover treatments as well as specifications of the surface albedo. In all the studies under consideration, differences in albedo specifica- tions for this region are negligible so that the issues of cloud parameterization schemes and evaluation of cloudiness (prescribed or predicted) become important. In addition, the pronounced annual variation in evaporation simulated with the UKMO model, for example, a feature missing in the observations, suggests some degree of physiological control on dry canopy evaporation in the dry season and consequently evaporation rates much less than potential. It is not possible to deduce, however, what effect differences in surface resistance formulations have upon the simulations.

In the case of the NCAR model results only, we have additional insight into possible causes for the high net radiation values. Shuttleworth and Dickinson (1989), following the study of Dickinson (1989), showed that the excessive levels of net radiation were primarily the result of high values of absorbed shortwave flux being calculated. This, in turn, could be related to several problems: (i) the daytime cloud cover assumed during tropical convection was too small, as was its persistence; (ii) the model used too low a cloud albedo; (iii) there was a failure to account for (possibly) the significant absorption of shortwave radiation by aerosols; (iv) the clear-sky absorption of shortwave radiation was underestimated. So here are some clues; the focus on shortwave fluxes also suggests a means of validating the longwave fluxes and in turn the net radiation, that is, to compare model simulations with clear-sky observations of net radiation at night or at high latitudes in winter when shortwave fluxes are zero. Such a comparison might serve to identify the relative roles of short and longwave fluxes to the overestimation of net radiation.

Shuttleworth and Dickinson (1989) also suggested that the overestimate in net radiation was not the only factor contributing to the overestimate of evaporation. Additionally, the NCAR model used in the simulations neglected to account for the spatial variability in convective precipitation; such variability is likely to reduce the effective interception of water by the canopy, and its water-holding capacity.

\section{c. Impact of model simplifications}

How are model simulations affected by simplifications to the boundary conditions used in the model integrations [e.g., use of constant sea surface temperatures (SSTs)] or by the use of simplified model schemes (e.g., in the cloud treatment or in the surface hydrology)? We choose the case of SSTs, because in the model simulations of Shukla et al. (1990), the NMC model was integrated with SSTs kept constant throughout the year. In contrast, Nobre et al. (1991) integrated the same model with varying SSTs (though these were prescribed). The annual cycles of precipitation and evaporation in Fig. 10 suggest that there is no significant impact of SSTs, which is consistent with the tendency for Amazonian rainfall to be mostly tied 
to evaporation rather than large-scale moisture convergence. This conclusion, however, may not apply to other regions of the globe.

In the case of cloud treatments, Shuttleworth and Dickinson (1989) have suggested the probable importance of cloud cover and cloud albedo calculations to the realistic simulation of surface net radiation. In Fig. 11 results are shown for models with a range of cloud treatments and cloud-cover assumptions (see Cess et al. 1990 for a description of GCM cloud schemes), but no significant correlation between cloud treatments and annual cycles is apparent. In theory, realistic simulations of surface radiation fluxes at least on the diurnal to monthly time scale can be expected only when clouds are predicted and based on interactions with radiation and other processes. For a thorough evaluation, much more information on the cloud calculations, and cloudiness data, are required, together with the radiation data, although the cloud and radiation data are probably available in many archived model datasets.

In the case of surface hydrology, there are a number of factors that will influence the simulations of regional evaporation and precipitation. Many hydrological processes are highly simplified in GCMs, for example, the spatial variability of soil properties and the rainfall, the runoff, the canopy interception, the soil infiltrability, and deep-soil percolation. Representation of these processes and the numerical constants set for the range of hydrological properties vary from model to model. They all influence the diurnal and seasonal variations in soil moisture, which in turn interact with the evaporation and precipitation fields, but in many of the studies referred to above soil moisture data are not given.

Even with a realistic representation of canopy and surface hydrological processes, a nonrealistic representation of the $A B L$ may adversely affect the climate simulation. The few model studies on deforestation illustrate the dominating impact of surface albedo and roughness effects on the precipitation and evaporation changes induced by deforestation. They also suggest that simulations depend critically upon the cloud calculations, and in many parts of the world, this would inevitably rely on our understanding of $\mathrm{ABL}$ clouds and their correct parameterization.

\section{Discussion and conclusions}

The paper has provided an overall summary of current GCM $A B L$ and surface schemes, and the main results from many sensitivity studies undertaken with GCMs in the last one to two decades. A range of GCM sensitivity studies has shown that regional and global climate depend on albedo, surface moisture and roughness, and the inclusion of vegetation. This suggests that there is a need to account for soils and vegetation effects, with an appropriate land-surface scheme for surface fluxes. One major requirement for realistic climate simulations in GCMs is the need for accurate surface fluxes at the appropriate horizontal resolution. The effects of subgrid orography on the drag and heat transfer have still to be evaluated and incorporated in many GCM schemes, however, and it is as yet unclear how much spatial surface detail is required for the lower boundary condition and what account needs to be taken of subgrid variability ( see Henderson-Sellers and Pitman 1992).

A number of tropical deforestation model studies in recent times have clarified the role of vegetation in simulating regional climate. These and other studies (e.g., Sud et al. 1990) have emphasized the impact of surface albedo and roughness on the simulations ${ }_{2}$ and have helped identify surface (canopy) hydrological processes and cloud processes requiring future critical attention in models. We refer particularly to the simulation in models of clouds, and to the calculation of mean cloudiness. There is evidence (Fig. 11 ) that most models overestimate the net radiation over Amazonia (the author has evidence that this is the case in other continental regions too), probably because of an underestimate of mean cloudiness and of clear-sky shortwave absorption rather than to the use of albedos that are too small. In a region such as Amazonia, where evaporation rates are close to potential for much of the year, incorrect simulation of the net radiation is likely to lead to errors both in the level of evaporation and in the partitioning of the available energy into sensible and latent heat fluxes. It is probable that the correct simulation of regional climate, and the response of that climate to imposed surface or atmospheric changes, depends to a great extent upon the realistic calculation of surface net radiation.

The preceding comments lend emphasis to the importance of observations to the validation of GCM simulations of the ABL and the diurnal variation of surface fluxes, soil temperature and moisture, and nearsurface air temperature. Long-term measurements of local fluxes and associated variables at specific locations within each continent are required, together with a means of evaluating the area-averaged quantities that are most compatible with the GCM simulated data. The problem of area averaging is greatly minimized if the atmospheric observations are made over extensive quasi-homogenous regions of vegetation or bare soil. Some such data are now available (e.g., Andre et al. 1986; Sato et al. 1989a), and there are prospects of many more through several large international field experiments planned during the nineties. At the monthly time scale, the climatological atlas of Henning (1989) serves as a valuable data source for the assessment of the regional surface energy balance simulated in models. What is urgently required is a thorough analysis of relevant net radiation observations, preferably at the diurnal and monthly time scales, and a critical evaluation of model performance so far as net 
radiation, and the surface energy balance, is concerned at the regional scale. This would then lead into the problem raised by Shuttleworth and Dickinson (1989) in the context of the NCAR GCM of cloud schemes and their contribution to uncertainties in surface net radiation.

This review suggests a number of recommendations for future work, as follows:

1) For a given GCM, more systematic studies of regional climate, with emphasis on the SEB and water budget, evaluation of the statistical significance of changes, and comparison where possible with observations, are required. Mean fields are often presented in the literature (e.g., Carson 1982a; Sud and Smith 1984, 1985a,b; Heasman 1987; Dickinson and Henderson-Sellers 1988; Slingo et al. 1989), but the need for comparisons with observations needs to be emphasized. Model performance must ultimately be assessed by how well observations are reproduced. The importance of satellite observations for validation cannot be overemphasized (e.g., Smith and Vonder Haar 1991).

2) Simulations of regional climate and comparisons with observations, in particular regarding the impact of imposed changes on near-surface properties, including meteorological and soil parameters require greater attention.

3) Careful assessment and comparative evaluation for several GCMs of each model's response to specific $\mathrm{ABL} /$ land-surface changes are required. There are three major tasks that confront the researcher so far as the development and validation of $\mathrm{ABL}$ and surface schemes in GCMs are concerned:

(i) There is a need to assess critically the impact of "improved" parameterization schemes on GCM simulations, taking into account the problem of natural variability and hence the statistical significance of the induced changes.

(ii) There is a need to compare GCM simulations of surface and ABL behavior (particularly regarding the diurnal cycle of surface fluxes, air temperature, and ABL depth) with observations over a range of surface types (vegetation, desert, ocean). In this context, area-average values of surface fluxes will be required to calibrate directly the $\mathrm{ABL} /$ land-surface scheme in the GCM.

(iii) There is a need for intercomparisons of ABL and land-surface schemes used in GCMs, both for one-dimensional stand-alone models and for GCMs that incorporate the respective schemes.

4) Studies of the simulation of net radiation and the surface energy balance in a range of models for a number of continental regions are required, with detailed comparisons of suitable observations.

5) Improvements of the parameterization of cloud processes and the calculation of cloudiness, are required insofar as these will lead to improved simulations of surface net radiation.

6) Improvements of the parameterization of surface runoff and canopy interception processes, and of the spatial distribution of rainfall over a grid area are required.

Acknowledgments. The author kindly acknowledges financial support from WMO for attendance at a workshop on climate and the boundary layer held at ECMWF during August 1989. Thanks also to the many individuals who responded to questionnaires and general queries regarding GCM parameterization schemes, and to J. C. Wyngaard for allowing the author access to the results of his (JCW's) own questionnaire. The net radiation values shown in Fig. 11 for the UKMO and NMC models were kindly provided by Dr. Jennifer Lean and Dr. David Straus, respectively.

\section{APPENDIX A}

\section{Surface Flux Formulations}

Use of a set of turbulent scaling parameters is at the very basis of Monin-Obukhov theory; the set is defined in terms of the surface fluxes,

$$
\begin{aligned}
& u_{*}=\left(\tau_{0} / \rho\right)^{1 / 2}, \\
& \theta_{*}=-H_{0} /\left(\rho c_{p} u_{*}\right), \\
& q_{*}=-E_{0} /\left(\rho u_{*}\right) .
\end{aligned}
$$

These scales are related to mean field variables as follows

$$
\begin{gathered}
u_{*}=\frac{k u_{a}}{\ln \left(z / z_{0}\right)-\Psi_{M}(z / L)}, \\
\theta_{*}=\frac{k \operatorname{Pr}^{-1}\left(\theta_{v a}-\theta_{0}\right)}{\ln \left(z / z_{T}\right)-\Psi_{H}(z / L)} .
\end{gathered}
$$

A similar relation to (A5) for the humidity scale $q_{*}$ can be written, with $\theta_{v a}-\theta_{0}$ replaced by $q_{a}-q_{0}$. In the Eqs. (A1)-(A5) $k$ is von Kármán's constant, $\operatorname{Pr}$ is a neutral turbulent Prandtl number, $z$ is height, $z_{0}$ and $z_{T}$ are aerodynamic roughness and temperature surface scaling lengths, respectively, and $L$ is the Monin-Obukhov stability length defined in terms of $u_{*}$ and $\theta_{*}$. Model schemes differ in their choice of $k, \operatorname{Pr}, z_{0} / z_{T}$, and $\Psi_{M, H}$.

Combination of Eqs. (A4) and (A5) allows the functions $F_{M}\left(=C_{D} / C_{D N}\right)$ and $F_{H}\left(=C_{H} / C_{H N}\right)$ to be expressed as

$$
\begin{aligned}
F_{M} & =\left(1-k^{-1} C_{D N}^{1 / 2} \psi_{M}(\zeta)\right)^{-2} \\
F_{H} & =F_{M}^{1 / 2}\left(1-k^{-1} \operatorname{Pr}_{H N} C_{D N}^{-1 / 2} \psi_{H}(\zeta)\right)^{-1} .
\end{aligned}
$$


TABLE A1. GCMs and ABL/land-surface schemes. For the ABL scheme, tc refers to turbulence closure and $K(l, \mathrm{Ri})$ refers to a first-order closure scheme based on mixing-length $(l)$ and Richardson number (Ri) formulations.

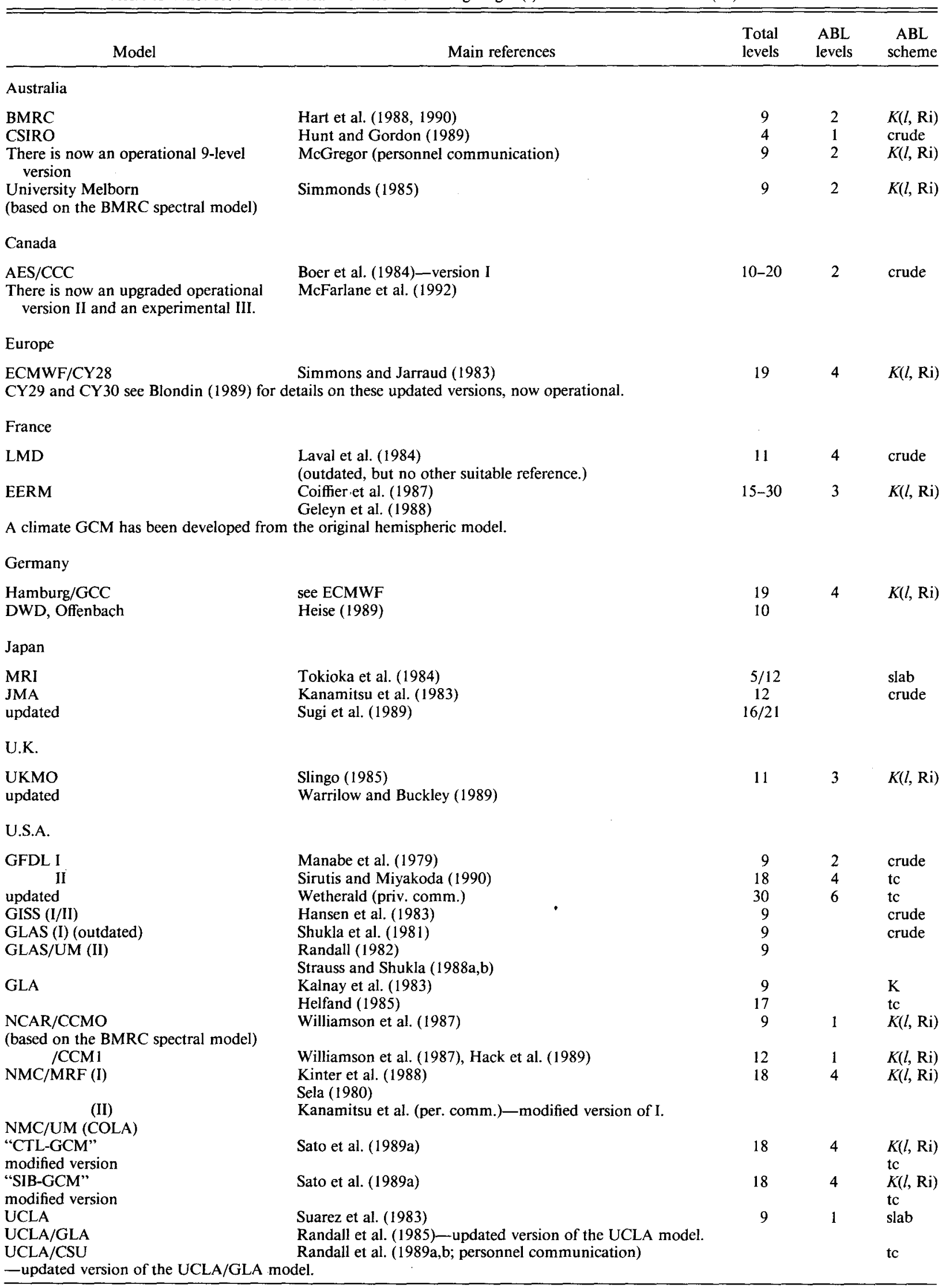


The $\Psi$ functions in Eqs. (A6) and (A7) can be readily written in terms of gradient functions $\Phi$, where

$$
\Psi=\int(1-\Phi(\zeta)) d(\ln \zeta)
$$

The $\Phi$ functions broadly take the form, for $\zeta \leqslant 0$,

$$
\begin{aligned}
& \Phi_{M}=\left(1-\gamma_{1} \zeta\right)^{-1 / 4}, \\
& \Phi_{H}=\operatorname{Pr}\left(1-\gamma_{2} \zeta\right)^{-1 / 2},
\end{aligned}
$$

and, for $\zeta>0$,

$$
\begin{aligned}
& \Phi_{M}=1+\gamma_{3} \zeta, \\
& \Phi_{H}=\operatorname{Pr}+\gamma_{4} \zeta .
\end{aligned}
$$

Major results and review recommendations are summarized in Table 1 of Garratt and Pielke (1989). For example, Dyer (1974) recommended the BusingerDyer forms (see also Businger 1988) with $k=0.4$ or $0.41, \operatorname{Pr}=1, \gamma_{1}=\gamma_{2}=16$, and $\gamma_{3}=\gamma_{4}=5$. These values are supported substantially in later reviews by, for example, Yaglom (1977) and Hogstrom (1988). This combination of constants approximates closely many of the results shown in Table 1 of Garratt and Pielke (1989), but differs significantly from that of Businger et al. (1971). There is thus considerable evidence to suspect the values of $k$ and $\operatorname{Pr}$ found by Businger et al. (1971).

\section{APPENDIX B}

\section{GCM Descriptions}

Information contained in this appendix serves to summarize several key aspects of many GCMs in use around the world. Relevant references are given in $\mathrm{Ta}$ ble A1, and in Table A2 the status of five key parameters and processes is indicated. The information is based on literature obtained from many GCM groups, visits by the author to some groups and correspondence with most of them, mostly through 1989 and 1990. In many cases, this information was cross-checked with questionnaire responses kindly made available by C. H. Moeng and J. C. Wyngaard of NCAR. Some information is still dependent on the open literature. Many models probably have more detailed options for a number of physical processes and probably have been run with these but still use the basic schemes for operational purposes and for long climate runs. The differences between the "standard" model as used for many kinds of simulations, and modified versions of the model used for special simulations, may be significant and a source of possible controversy.

Several points should be noted:

(i) US OSU and the Chinese IAP (based on the US OSU model) models are not included.

(ii) GISS model does have a crude vegetation scheme used in sensitivity experiments.
TABLE A2. Indication of four features in the GCMs summarized in Table Al, including the diurnal cycle; terrestrial roughness length (var $=$ variable; const $=$ constant); soil temperature, $T_{s}$ (forcing $=$ prognostic $\mathrm{SEB}$ with zero subsurface heat flux; $\operatorname{diagSEB}=$ diagnostic

\begin{tabular}{|c|c|c|c|c|c|}
\hline Model & Diurnal & $\begin{array}{c}z_{0} \\
(\mathrm{~m})\end{array}$ & $T_{s}$ & $\eta$ & Veg \\
\hline BMRC & optional & 0.17 & $3-1$ & b & no \\
\hline CSIRO (4 level) & yes & $C_{d}$ const & forcing & $2-1$ thin & no \\
\hline CSIRO (9 level) & yes & 0.016 & $2-1$ thin & $2-1$ thin & no \\
\hline Univ. Melb. & & 0.30 & - & - & 一 \\
\hline $\begin{array}{l}\text { AES/CCC } \\
\text { version II }\end{array}$ & yes & $C_{d}$ var & & $\begin{array}{c}b \\
\text { (var cap) }\end{array}$ & no \\
\hline $\begin{array}{l}\text { ECMWF } \\
(\text { CY29, 30) }\end{array}$ & yes & var & $3-1$ & $3-1$ & yes \\
\hline LMD & no & var & $2-1$ thin & $2-1$ thin & yes \\
\hline EERM & yes & - & & - & - \\
\hline Hamburg/GCC & $\begin{array}{r}\text { linked } \\
\mathrm{ECM}\end{array}$ & $\begin{array}{l}\text { with } \\
\text { IWF }\end{array}$ & & & \\
\hline DWD & - & - & & - & 一 \\
\hline MRI & yes & 0.45 & & b & no \\
\hline JMA & yes & var & ? & $?$ & no \\
\hline UKMO & yes & var & $4-1$ & b & yes \\
\hline $\begin{array}{l}\text { GFDL I } \\
\text { II as above }\end{array}$ & optional & 0.17 & $\begin{array}{l}\text { diagSEB } \\
3-1\end{array}$ & b & $\begin{array}{l}\text { no } \\
\text { yes }\end{array}$ \\
\hline GISS & yes & var & $2 / 3-1$ & $2-1$ thin & no \\
\hline GLAS/UM & yes & 0.45 & forcing & $\mathrm{b}$ & no \\
\hline $\begin{array}{l}\text { GLA } \\
\text { (has SiB as opti } \\
\text { special simulat }\end{array}$ & $\begin{array}{l}\text { yes } \\
\text { on for } \\
\text { ions) }\end{array}$ & - & forcing & $\mathrm{b}$ & no \\
\hline $\begin{array}{l}\text { NCAR/CCMI } \\
\text { (has BATS as opt } \\
\text { special simulat }\end{array}$ & $\begin{array}{l}\text { no } \\
\text { tion for } \\
\text { ions) }\end{array}$ & 0.25 & $\begin{array}{l}\text { diagSEB } \\
G=0\end{array}$ & b & no \\
\hline $\begin{array}{l}\text { NMC/UM } \\
(+\mathrm{SiB})\end{array}$ & $\begin{array}{l}\text { yes } \\
\text { as above }\end{array}$ & var & $\begin{array}{l}3-1 \\
2-1 \text { thin }\end{array}$ & $3-1^{b}$ & $\begin{array}{l}\text { no } \\
\text { yes }\end{array}$ \\
\hline UCLA/GLA & yes & const & 2-1 thin & - & no \\
\hline $\begin{array}{l}\text { UCLA/CSU } \\
\text { (SiB option) }\end{array}$ & yes & var & $2-1$ thin & $3-1$ & yes \\
\hline
\end{tabular}
SEB with unspecified $G$ calculation, unless $G=0 ; 2-1$ thin $=$ forcerestore method; 3-l or 4-1 $=3$ - or 4-layer soil scheme); soil moisture, $\eta(b=$ bucket; $2-1$ thin $=$ force restore; $3-1=$ three-layer soil scheme; var cap = variable capacity); presence of vegetation (veg).

(iii) GISS model interpolates the $1-\mathrm{km}$ wind and surface to give a reference near-surface wind using an Ekman turning assumption.

(iv) CSIRO 4-level model interpolates the first level $(\approx 1 \mathrm{~km})$ and surface to give reference near-surface properties. There is now an operational 9-level model, both models having the option of a soil-canopy scheme.

(v) The MRI model is based on the UCLA model.

(vi) The NCAR CCMO model is originally based on the BMRC model.

(vii) The Hamburg GCC is closely linked to the ECMWF model.

\section{REFERENCES}

Abramopoulos, F., C. Rosenzweig, and B. Choudhury, 1988: Improved ground hydrology calculations for global climate models (GCMs): Soil water movement and evapotranspiration. J. Climate, 1, 921-941.

Andre, J. C., 1983: Planetary boundary layer parameterization and turbulence closure. Mesoscale Meteorology-Theories, Obser- 
vations and Models, D. K. Lilly and T. Gal-Chen, Eds., D. Reidel, $651-669$.

- J. J. Goutorbe, and A. Perrier, 1986: HAPEX-MOBILHY: A hydrologic atmospheric experiment for the study of water budget and evaporation flux at the climatic scale. Bull. Amer. Meteor. Soc., 67, 138-144.

_- P. Bougeault, and J. P. Goutorbe, 1990: Regional estimates of heat and evaporation fluxes over non-homogeneous terrain. Examples from the HAPEX-MOBILHY programme. Bound.Layer Meteor., 50, 77-108.

Arya, S. P. S., 1977: Suggested revisions to certain boundary layer parameterization schemes used in atmospheric circulation models. Mon. Wea. Rev., 105, 215-227.

Avissar, R., and M. M. Verstraete, 1990: The representation of continental surface processes in atmospheric models. Rev. Geophys., 28, 35-52.

Bengtsson, L., M. Kanamitsu, P. Kallberg, and S. Uppala, 1982: FGGE 4-dimensional data assimilation at ECMWF. Bull. Amer. Meteor. Soc., 63, 29-43.

Bhumralkar, C. M., 1975: Numerical experiments on the computation of ground surface temperature in atmospheric general circulation models. J. Appl. Meteor., 14, 1246-1258.

Blackadar, A. K., 1979: High-resolution models of the planetary boundary layer. Advances in Environmental Science and Engineering, Vol. 1, J. R. Pfafflin and E. N. Zeigler, Eds., Gordon and Breach, 50-85.

Blondin, C., 1989: Research on land-surface parameterization schemes at ECMWF. Proc. Workshop ECMWF, 24-26 October 1988, Reading, UK, ECMWF, 207-234.

Boer, G. J., N. A. McFarlane, R. Laprise, J. D. Henderson, and J. P. Blanchet, 1984: The Canadian Climate Centre spectral atmospheric general circulation model. Atmos.-Ocean, 22, 397429.

ulated by 14 atmospheric general circulation models. CAS/JSC Working Group on Numerical Experimentation. WCRP-58, WMO/TD No. 425, World Meteorological Organization, Geneva, $156 \mathrm{pp}$.

Brutsaert, W., 1982: Evaporation into the Atmosphere. D. Reidel, $299 \mathrm{pp}$.

Businger, J. A., 1973: Turbulent transfer in the atmospheric surface layer. Workshop in Micrometeorology, D. A. Haugen, Ed., Amer. Meteor. Soc., 67-100.

- 1988: A note on the Businger-Dyer profiles. Bound-Layer Meteor., 42, 145-151.

- - J. C. Wyngaard, Y. Izumi, and E. F. Bradley, 1971: Fluxprofile relationship in the atmospheric surface layer. J. Atmos. Sci., 28, 181-189.

Carson, D. J., 1982a: Comments on the sensitivity of numerical simulations to different parameterizations of the boundary-layer properties and processes. Proc. Workshop on PBL Parameterization, Reading, UK, ECMWF, 119-154.

- $1982 \mathrm{~b}$ : Current parameterizations of land-surface processes in atmospheric general circulation models. Land Surface Processes in Atmospheric General Circulation Models. P. S. Eagleson, Ed., C.U.P., 67-108.

- 1986: Parametrizations of land-surface processes in Meteorological Office numerical weather prediction and climate models. Tech Note No. 37, UK Met. Office Dyn. Clim., 30 pp.

- , and A. B. Sangster, 1981: The influence of land-surface albedo and soil moisture on GCM circulations. Numerical Experimentation Programme Report No. 2, UK Meteor. Office, Bracknell, 5.14-5.21.

Cess, R. D., and coauthors, 1989: Interpretation of cloud-climate feedback as produced by 14 atmospheric general circulation models. Science, 245, 513-516.

$\longrightarrow$, and coauthors, 1990: Intercomparison and interpretation of climate feedback processes in 19 atmospheric general circulation models. J. Geophys. Res., 95D, 16 601-16 615.

Charney, J. G., 1975: Dynamics of deserts and droughts in the Sahel. Quart. J. Roy. Meteor. Soc., 101, 193-202.
- W. J. Quirk, S. H. Chow, and J. Kornfield, 1977: A comparative study of the effects of albedo change on drought in semi-arid regions. J. Atmos. Sci., 34, 1366-1385.

Chervin, R. M., 1979: Response of the NCAR GCM to changed land surface albedo. Rep. of the JOC Study Conf. on Climate Models: Performance, intercomparison and sensitivity studies, 1: 563581.

Clarke, R. H., 1970: Recommended methods for the treatment of boundary layer in numerical models. Aust. Meteor. Mag., 18, 51-73.

—- A. J. Dyer, R. R. Brook, D. G. Reid, and A. J. Troup, 1971: The Wangara Experiment: Boundary-layer data. Tech. Paper No. 19, Div. Meteor. Physics, CSIRO, Australia, 21 pp.

Coiffier, J., Y. Ernie, J. F. Geleyn, J. Clochard, J. Hoffman, and F. Dupont, 1987: The operational hemispheric model at the French meteorological service. J. Meteor. Soc. Japan, Special NWP Symp. Vol., 337-345.

Cunnington, W. M., and P. R. Rowntree, 1986: Simulations of the Saharan atmosphere-Dependence on moisture and albedo. Quart. J. Roy. Meteor. Soc., 112, 971-999.

Deacon, E. L., 1953: Vertical profiles of mean wind in the surface layers of the atmosphere. Geophys. Mem., 91, $64 \mathrm{pp}$.

Deardorff, J. W., 1972: Parameterization of the PBL for use in GCMs. Mon. Wea. Rev., 100, 93-106.

_- 1974: Three-dimensional numerical study of the height and mean structure of a heated planetary boundary layer. Bound.Layer Meteor., 7, 81-106.

_ 1976: On the entrainment rate of a stratocumulus-topped mixed layer. Quart. J. Roy. Meteor. Soc., 102, 563-582.

_- 1977: A Parameterization of ground-surface moisture content for use in atmospheric prediction models. J. Appl. Meteor., 16, 1182-1185.

- 1 1978: Efficient prediction of ground surface temperature and moisture, with inclusion of a layer of vegetation. J. Geophys. Res., 83C, 1889-1903.

Delsol, F., F. Miyakoda, and R. H. Clarke, 1971: Parameterized processes in the surface boundary layer of an atmospheric circulation model. Quart. J. Roy. Meteor. Soc., 97, 181-208.

Dickinson, R. E., 1984: Modeling evapotranspiration for three-dimensional global climate models. Climate Processes and Climate Sensitivity. Geophys. Monogr., No. 29, Amer. Geophys. Union, $58-72$.

- 1988: The Force-restore model for surface temperature and its generalizations. J. Climate, 1, 1086-1097.

__ 1989: Implications of tropical deforestation for climate: A comparison of model and observational descriptions of surface energy and hydrological balance. Phil. Trans. Roy. Soc. Lond., B324, 423-431.

- , and A. Henderson-Sellers, 1988: Modelling tropical deforestation: A study of GCM land-surface parameterizations. Quart. J. Roy. Meteor. Soc., 114, 439-462.

- - _ - P. J. Kennedy, and M. F. Wilson, 1986: Biosphere-atmosphere transfer scheme (BATS) for the NCAR community climate model. NCAR Technical Note, NCAR/TN-275+STR, $69 \mathrm{pp}$.

Dorman, J. L., and P. J. Sellers, 1989: A global climatology of albedo, roughness length and stomatal resistance for atmospheric general circulation models as represented by the simple biosphere model (SiB). J. Appl. Meteor., 28, 833-855.

Dyer, A. J., 1974: A review of flux-profile relationships. Bound-Layer Meteor., 7, 363-372.

Esbensen, S. K., and Y. Kushnir, 1981: The heat budget of the global ocean. Clim. Res. Inst. Rep. No. 29, Oregon State Univ., Corvalis, USA 27 pp. [+ maps]

Garratt, J. R., 1977: Review of drag coefficients over oceans and continents. Mon. Wea. Rev., 105, 915-929.

, 1978: Transfer characteristics for a heterogeneous surface of large aerodynamic roughness. Quart. J. Roy. Meteor. Soc., 104, 491-502.

, 1980: Surface influence upon vertical profiles in the atmospheric near-surface layer. Quart. J. Roy. Meteor. Soc., 106, 803-819. 
___ 1992: The Atmospheric Boundary Layer. Cambridge University Press, 316 pp.

- , and B. B. Hicks, 1973: Momentum, heat and water vapour transfer to and from natural and artificial surfaces. Quart. J. Roy. Meteor. Soc., 99, 680-687.

- , and R. A. Pielke, 1989: On the sensitivity of mesoscale models to surface-layer parameterization constants. Bound.-Layer Meteor., 48, 377-387.

Geleyn, J. F., and H. J. Preuss, 1983: A new data set of satellitederived surface albedo values for operational use at ECMWF. Arch. Meteor. Geophys. Bioklimatol., A32, 353-359.

$\longrightarrow$, P. Bougeault, M. Rochas, D. Cariolle, J. P. Lafore, J. F. Royer, and J. C. Andre, 1988: The evolution of numerical weather prediction and atmospheric modelling at the French Weather Service. J. Theor. Appl. Mech., 7 (Special Issue, Supp. No. 2), 87110.

Hack, J. J., L. M. Bath, G. S. Williamson, and B. A. Boville, 1989: Modifications and enhancements to the NCAR community climate model (CCM1). NCAR Technical Note, NCAR/TN$336+$ STR, 144 pp.

Hansen, J., G. Russell, D. Rind, P. Stone, A. Lacis, S. Lebedeff, R. Ruedy, and L. Travis, 1983: Efficient 3-D global models for climate studies: Models I and. II. Mon. Wea. Rev., 111, 609662 .

Hart, T. L., W. Bourke, B. J. McAvaney, J. L. McGregor, and B. W. Forgan, 1988: Atmospheric general circulation simulations with the BMRC global spectral model: The impact of revised physical parameterizations. Bur. Met. Res. Centre Res. Rep. No. 12, 90 pp. [Available from B.M.R.C., P.O. Box 1289K, Melbourne, Victoria 3001.]

$\longrightarrow, \longrightarrow,-, \longrightarrow$, and,- 1990 : Atmospheric general circulation simulations with the BMRC global spectral model: The impact of revised physical parameterizations. J. Climate, 3, 436459.

Heasman, C. C., 1987: Sensitivity of the Met O 20 11-layer model to increased land surface roughness length. UK Met. Office Dyn. Clim., Tech. Note No. 49, 30 pp.

Heise, E., 1989: Experimentation with a surface model at the German Weather Service. Proc. Workshop ECMWF, 24-26 October 1988, Reading, UK, ECMWF, 207-234.

Helfand, H. M., 1985: A new scheme for the parameterization of the turbulent planetary boundary layer in the GLAS fourth order GCM. Preprints, Seventh Conf. on NWP, Montreal, Canada, Amer. Meteor. Soc., 348-354.

Henderson-Sellers, A., and M. F. Wilson, 1983: Surface albedo data for climatic modelling. Rev. Geophys. Space Phys., 21, 17431778 .

—_, and V. Gornitz, 1984: Possible climatic impacts of land cover transformations, with particular emphasis on tropical deforestation. Clim. Change, 6, 231-257.

$\longrightarrow$, and A. J. Pitman, 1992: Land-surface schemes for future climate models: Specification, aggregation, and heterogeneity, J. Geophys. Res., 97D, 2687-2696.

-, M. F. Wilson, G. Thomas, and R. E. Dickinson, 1986: Current global land surface data sets for use in climate related studies. NCAR Tech. Note, TN-272+STR, 110 pp.

Henning, D., 1989: Atlas of the Surface Heat Balance of the Continents. Gebrueder Borntraeger, $402 \mathrm{pp}$.

Hicks, B. B., 1973: Eddy fluxes over a vineyard. Agric. Meteor., 12, 203-215.

Hogstrom, U., 1988: Non-dimensional wind and temperature profiles in the atmospheric surface layer: A re-evaluation. Bound.-Layer Meteor., 42, 55-78.

Holloway, J. L., and S. Manabe, 1971: Simulation of climate by a global general circulation model. Part 1: Hydrological cycle and heat balance. Mon. Wea. Rev., 99, 335-370.

Hummel, J. R., and R. A. Reck, 1979: A global surface albedo model. J. Appl. Meteor., 18, 239-253.

Hunt, B. G., and H. B. Gordon, 1989: Diurnally varying regional climatic simulations. Int. J. Climatol., 9, 331-356.

Hwang, P. H., L. L. Stowe, H. Y. M. Yeh, H. L. Kyle, and coauthors,
1988: The Nimbus 7 global cloud climatology. Bull. Amer. Meteor. Soc., 69, 743-752.

Idso, S. B., J. K. Aase, and R. D. Jackson, 1975: Net radiation-Soil heat flux relations as influenced by soil water content variations. Bound.-Layer Meteor., 9, 113-122.

Izumi, Y., 1971: Kansas 1968 field program data report. Air Force Cambridge Res. Lab. Environ. Res. Papers No. 379, AFCRL72-0041, 79 pp.

Jaeger, L., 1976: Monatskarten des Niederschlags fuer die ganze Erde. Ber. Disch. Wetterdienstes, 18, 38 pp.

- 1983: Monthly and areal patterns of mean global precipitation. Variations in the Global Water Budget, A. Street-Perrott, M. Beran, and R. Ratcliffe, Eds., D. Reidel, 129-140.

Jarvis, P. G., 1976: The interpretation of the variations in leaf water potential and stomatal conductance found in canopies in the field. Phil. Trans. Roy. Soc. London, B273, 593-610.

- , and K. G. McNaughton, 1986: Stomatal control of transpiration: Scaling up from leaf to region. Adv. Ecol. Res., 15, 1-49.

Kalnay, E., R. Balgovind, W. Chao, D. Edelmann, J. Pfaendtner, L. Takacs, and K. Takano, 1983: Documentation of the GLAS fourth order general circulation model. Vol. 1, Model documentation. NASA Tech. Memo. No. 86064, 381 pp.

Kanamitsu, M., K. Tada, T. Kudo, N. Sato, and S. Isa, 1983: Description of the JMA operational spectral model. J. Meteor. Soc. Japan, 61, 812-828.

Kinter, J. L., J. Shukla, L. Marx, and E. K. Schneider, 1988: A simulation of the winter and summer circulations with the NMC global spectral model. $J$. Atmos. Sci., 45, 2486-2522.

Kriebel, K. T., 1979: Albedo of vegetated surfaces: Its variability with differing irradiances. Remote Sens. Environ., 8, 283-290.

Kurbatkin, G. P., S. Manabe, and D. G. Hahn, 1979: The moisture content of the continents and the intensity of summer monsoon circulation. Soviet Meteorol. and Hydrol., 11, 1-6.

Laval, K., 1986: General circulation model experiments with surface albedo changes. Clim. Change, 9, 91-102.

_- 1988: Land surface processes. Physically-based Modelling and Simulation of Climate and Climatic Change-Part 1, M. E. Schlesinger, Ed., Kluwer Acad., 285-306.

of the Sahel on climate. J. Atmos. Sci., 43, 2418-2429.

_- C. Ottle, A. Perrier, and Y. Serafini, 1984: Effect of parameterization on climate simulated by a GCM. New Perspectives in Climate Modelling. A. L. Berger and C. Nicolis, Eds., Elsevier, 223-247.

Lean, J., and D. A. Warrilow, 1989: Simulation of the regional climatic impact of Amazon deforestation. Nature, 342, 411-413.

Louis, J. F., 1979: A parametric model of vertical eddy fluxes in the atmosphere. Bound.-Layer Meteor., 17, 187-202.

- , M. Tiedtke, and J. F. Geleyn, 1982: A short history of the PBI parameterizations at ECMWF. Proc. 1981 ECMWF Workshop on PBL Parameterisation, Reading, UK, ECMWF, 59-71.

McFarlane, N. A., G. J. Boer, J.-P. Blanchet, and M. Lazare, 1992: The Canadian Climate Centre second-generation general circulation model and its equilibrium climate. J. Climate, 5, 10131044.

Mahrt, L., and H. Pan, 1984: A two-layer model of soil hydrology. Bound.-Layer Meteor., 29, 1-20.

Manabe, S., 1969: The atmospheric circulation and the hydrology of the earth's surface. Mon. Wea. Rev., 97, 739-774.

- -1975 : A study of the interaction between the hydrological cycle and climate using a mathematical model of the atmosphere. Proc. Conf. on Weather and Food, MIT, Cambridge $10 \mathrm{pp}$.

- , D. G. Hahn, and J. L. Holloway, 1979: Climate simulations with GFDL spectral models of the atmosphere: Effect of spectral truncation. JOC Study Conference on Climate Models Rep. GARP No. 22, 1, 41-94.

Matthews, E., 1983: Global vegetation and land use: New high-resolution data bases for climate studies. J. Climate Appl. Meteor., 22, 474-487.

-, 1985: Atlas of archived vegetation, land-use and seasonal albedo data sets. NASA Tech. Memo. 86199, 53 pp. 
Meehl, G. A., and W. M. Washington, 1988: A comparison of soilmoisture sensitivity in two global climate models. J. Atmos. Sci., 45, 1476-1492.

Mellor, G. L., and T. Yamada, 1974: A hierarchy of turbulence closure models for planetary boundary layers. J. Atmos. Sci., 31, 17911806 [Corrigenda, 1977: J. Atmos. Sci., 34, 1482.]

_- and —-, 1982: Development of a turbulence closure model for geophysical fluid problems. Rev. Geophys. Space Phys., 20, $851-875$.

Miller, M. J., T. N. Palmer, and R. Swinbank, 1989: Parametrization and influence of subgridscale orography in general circulation and numerical weather prediction models. Meteorol. Atmos. Phys., 40, 84-109.

Mintz, Y., 1984: The sensitivity of numerically simulated climates to land-surface boundary conditions. Global Climate, J. T. Houghton, Ed., C.U.P., 79-105.

_- and Y. V. Serafini, 1989: Global monthly climatology of soil moisture and water balance. Internal Note No. 148, Laboratoire de Meteorologie Dynamique, CNRS, Paris, 45 pp.

Miyakoda, K., and J. Sirutis, 1977: Comparative integrations of global models with various parameterized processes of subgrid-scale vertical transports: Description of the parameterizations. Beitr. Phys. Atmos., 50, 445-487.

- and R. F. Strickler, 1981: Cumulative results of extended forecast experiment. Part III: Precipitation. Mon. Wea. Rev., 109, 830-842.

Mylne, M. F., and P. R. Rowntree, 1991: Deforestation of Amazonia-Modelling the effects of albedo change. Clim. Res. Tech. Note CRTN 7, Hadley Centre, UK Met. Office, Bracknell, 39 pp.

Nieuwstadt, F. T. M., and H. Tennekes, 1981: A rate equation for the nocturnal boundary-layer height. J. Atmos. Sci., 38, 14181428.

Nobre, C. A., P. J. Sellers, and J. Shukla, 1991: Amazonian deforestation and regional climate change. J. Climate, 4, 957-988.

Noilhan, J., and S. Planton, 1989: A simple parameterization of land surface processes for meteorological models. Mon. Wea. Rev., 117, 536-549.

Oguntoyinbo, J. S., 1970: Reflection coefficient of natural vegetation, crops and urban surfaces in Nigeria. Quart. J. Roy. Meteor. Soc., 96, 430-441.

Oort, A. H., 1983: Global atmospheric circulation statistics, 19581973. NOAA Prof. Paper No. 14, $180 \mathrm{pp}$.

Perrier, A., 1982: Land-surface processes: Vegetation. Land Surface Processes in Atmospheric General Circulation Models, P. S. Eagleson, Ed., C.U.P., 395-448.

Pinker, R. T., O. E. Thompson, and T. F. Eck, 1980: The albedo of a tropical evergreen forest. Quart. J. Roy. Meteor. Soc., 106, 551-558.

Pitman, A. J., A. Henderson-Sellers, and J. G. Cogley, 1989: Global data sets for land surface schemes and experience in the incorporation of vegetation into general circulation models. Proc. ECMWF Workshop on Parameterization of Fluxes over Land Surface, Oct. 1988, Reading, UK, ECMWF, 345-370.

- - _- and Z-L. Yang, 1990: Sensitivity of regional climates to localized precipitation in global models. Nature, 346, 734-737.

—_, Z. L. Yang, J. G. Cogley, and A. Henderson-Sellers, 1991: Description of bare essentials of surface transfer for the Bureau of Meteorology Research Centre AGCM. Bur. Meteor. Res. Centre Res. Rep. No. 32, 86 pp. [Available from B.M.R.C., P.O. Box 1289K, Melbourne, Victoria 3001, Australia.]

Posey, J. W., and P. F. Clapp, 1964: Global distribution of normal surface albedos. Geofis. Int., 4, 33.

Priestley, C. H. B., and R. J. Taylor, 1972: On the assessment of surface heat flux and evaporation using large-scale parameters. Mon. Wea. Rev., 100, 81-92.

Randall, D. A., 1982: Monthly and seasonal simulations with the GLAS climate model. Proc. Workshop on Intercomparison of Large-Scale Models Used for Extended Range Forecasts, Reading, UK, ECMWF, 107-166.

___ J. A. Abeles, and T. G. Corsetti, 1985: Seasonal simulations of the PBL and boundary-layer stratocumulus clouds with a GCM. J. Atmos. Sci., 42, 641-676.

$\longrightarrow$, P. Sellers, and D. A. Dazlich, 1989a: Applications of a prognostic turbulence kinetic energy in a bulk boundary-layer model. Paper No. 437, Dept. of Atmospheric Science, Col. State Univ., $19 \mathrm{pp}$.

- Harshvardhan, D. A. Dazlich, and T. G. Corsetti, 1989b: Interactions among radiation, convection, and large-scale dynamics in a general circulation model. J. Atmos. Sci., 46, 1943-1970.

__ , and coauthors, 1992: Intercomparison and interpretation of surface energy fluxes in atmospheric general circulation models. J. Geophys. Res., 97, 3711-3724.

Raupach, M. R., and J. J. Finnigan, 1988: Single-layer models of evaporation from plant canopies are incorrect but useful, whereas multilayer models are correct but useless: Discuss. Aust. J. Plant Physiol., 15, 705-716.

Rowntree, P. R., 1983: Sensitivity of general circulation models to land surface processes. Proc. Workshop on Intercomparison of Large-scale Models used for Extended Range Forecasts, Reading, UK, ECMWF, 107-166.

- 1988: Review of GCMs as a basis for predicting the effects of vegetation change on climate. Forests, Climate, and HydrologyRegional Impacts, E. R. C. Reynolds and F. B. Thompson, Eds., The United Nations Univ., 162-196.

_- and J. A. Bolton, 1983: Simulation of the atmospheric response to soil moisture anomalies over Europe. Quart. J. Roy. Meteor. Soc., 109, 501-526.

Sato, N., P. J. Sellers, D. A. Randall, E. K. Schneider, J. Shukla, J. L. Kinter III, Y.-T. Hou, and E. Albertazzi, 1989a: Implementing the simple biosphere model $(\mathrm{SiB})$ in a general circulation model: Methodologies and results. NASA Report 185509, 76 pp.

$-,-,-,-,-\longrightarrow,-,-$, and,$- 1989 \mathrm{~b}$ : Effects of implementing the simple biosphere model in a general circulation model. J. Atmos. Sci., 46, 2757-2782.

Sela, J. G., 1980: Spectral modeling at the National Meteorological Center. Mon. Wea. Rev., 108, 1279-1292.

Sellers, P. J., and J. L. Dorman, 1987: Testing the simple biosphere model ( $\mathrm{SiB}$ ) using point micrometeorological and biophysical data. J. Appl. Meteor., 26, 622-651.

—, Y. Mintz, Y. C. Sud, and A. Dalcher, 1986: A simple biosphere model ( $\mathrm{SiB}$ ) for use within general circulation models. J. Atmos. Sci., 43, 505-531.

Shukla, J., and Y. Mintz, 1982: Influence of land-surface evapotranspiration on the earth's climate. Science, 215, 1498-1501.

- D. Straus, D. Randall, Y. Sud, and L. Marx, 1981: Winter and summer simulations with the GLAS climate model. NASA Tech Memo. 83866, GSFC, Greenbelt, MD. 282 pp.

- C. Nobre, and P. Sellers, 1990: Amazon deforestation and climate change. Science, 247, 1322-1325.

Shuttleworth, W. J., 1988: Evaporation from Amazonian rainforest. Proc. Roy. Soc. London, B233, 321-346.

$\longrightarrow$, and J. S. Wallace, 1985: Evaporation from sparse crops-An energy combination theory. Quart. J. Roy. Meteor. Soc., 111, 839-855.

, and R. E. Dickinson, 1989: Comments on "Modelling tropical deforestation: A study of GCM land-surface parametrizations" by R. E. Dickinson and A. Henderson-Sellers. Quart. J. Roy. Meteor. Soc., 115, 1177-1179.

- and coauthors, 1984a: Observations of radiation exchange above and below Amazonian forest. Quart. J. Roy. Meteor. Soc., 110, $1163-1169$.

- and coauthors, 1984b: Eddy correlation of energy partition for Amazonian forest. Quart. J. Roy. Meteor. Soc., 110, 1143-1162.

Simmonds, I., 1985: Analysis of the "spinup" of a general circulation model. J. Geophys. Res., 90D, 5637-5660.

Simmons, A. J., and M. Jarraud, 1983: ECMWF seminar on numerical methods for weather prediction. Vol. 2. 113-165.

Sirutis, J., and K. Miyakoda, 1990: Subgrid scale physics in 1-month forecasts. Part 1: Experiment with four parameterization packages. Mon. Wea. Rev., 118, 1043-1064. 